\title{
Review Article Self-Organizing Processes in Landscape Pattern and Resilience: A Review
}

\author{
Donald L. DeAngelis \\ Biology Department, University of Miami, Coral Gables, FL 33124, USA \\ Correspondence should be addressed to Donald L.DeAngelis, don_deangelis@usgs.gov
}

Received 27 August 2012; Accepted 24 October 2012

Academic Editors: S. C. Dekker, H. Sanderson, and C. J. Topping

Copyright ( $) 2012$ Donald L. DeAngelis. This is an open access article distributed under the Creative Commons Attribution License, which permits unrestricted use, distribution, and reproduction in any medium, provided the original work is properly cited.

\begin{abstract}
Environmental conditions influence the way different types of vegetation are distributed on various scales from the landscape to the globe. However, vegetation does not simply respond passively but may influence its environment in ways that shape those distributions. On the landscape scale, feedbacks from vegetation can lead to patterns that are not easily interpreted as merely reflecting external abiotic conditions. For example, sharp ecotones exist between two vegetation types, even if the basic abiotic gradient is slight, somewhere along the gradient. These are observed in transitions between numerous pairs of ecosystem types, such as tree/grassland, tree/mire, tree tundra, and halophytic plants/glycophytic plants. More complex spatial vegetation patterns may also exist, such as alternating stripes or irregular patterns of either two types of vegetation or vegetation and bare soil. One purpose of this paper is to emphasize that these two types of patterns, sharp ecotones between vegetation types and large-scale landscape patterns of vegetation, both have a common basis in the concept of bistability, in which alternative stable states can occur on an area of land. Another purpose is to note that an understanding of the basis of these patterns may ultimately help in management decisions.
\end{abstract}

\section{Introduction}

A fundamental goal of ecology is to understand the processes underlying the patterns found in nature [1]. Understanding the spatial patterns of vegetation has been a prominent area of study, as large areas of the earth's surface are characterized by vegetation patterns that are not easily explainable as consequences of variations in the underlying abiotic environment. One striking feature of vegetation is the transitional zone, or ecotone, between vegetation of different types or species. Ecotones are often found along gradients of certain environmental factors that are far sharper than can be explained by the changes in the underlying gradient, which suggests that active biological processes, not just passive response, are involved in determining the ecotone. Other landscape features that have attracted much attention are regular or irregular spatial vegetation patterns that are often observed on areas that are virtually homogeneous in external abiotic properties; that is, abiotic properties not created by feedback of the vegetation. These features include the "tiger bush" of sub-Saharan Africa [2] and the "string" patterns in boreal peatlands [3]. The patterns of this type that have been studied usually involve one vegetation type that forms some regular (e.g., evenly spaced lines) or irregular shapes, alternating with bare soil or sediment, or with another type of vegetation. These two types of spatial features of vegetation, sharp ecotones and spatial patterns, have been studied separately in the past, but because the fundamental processes maintaining them are similar, it is logical to consider these patterns together.

The development of both types of features is based on the possible existence of alternative stable states of vegetation on a particular area of land (generalized to include areas of seabed, etc.), a phenomenon called bistability. These alterative stable states are stabilized by positive feedbacks and can resist change, or are resilient to some degree. Positive feedbacks have traditionally received less attention than negative feedbacks in ecology [4], but have been recognized as being essential in the formation of spatial patterns based on alternative stable states (e.g., [5-7]). 
Positive feedback arises when the response of a system to an initial deviation of the system acts to reinforce the change in the direction of the deviation. For example, the growth in size of one species population can exert a competitive effect on another species population (e.g., one plant population shading the other from light), which can drive the latter to smaller levels of biomass, which itself feeds back positively, or in a self-reinforcing way, on the growth of the first species population. Positive feedback can also occur indirectly by one species population decreasing the supply of available nutrients to the other, or by producing some inhibitor, such as a toxin that kills or slows the growth of the other species. Such direct or indirect competitive effects occur not only between different species or different vegetation types (e.g., single species or assemblages of species), but also within one species or vegetation type; that is, intraspecifically. In both cases, alternative stable states may be the outcome under certain circumstances. Consider the case of two different types of vegetation that could in principle occupy the same area of land. If each type can produce positive, selfreinforcing feedbacks that resist invasion by the other type, these two vegetation types could occur as alternative stable states on the same landscape. As another example, consider the case in which vegetation of one type in one location can cause a depletion of resources or produce an inhibitor that suppresses vegetation in another location. This creates conditions that can lead to a pattern of alternating states of vegetation and bare soil or sediment on a landscape.

Such patterns as sharp ecotones and landscape vegetation patterns occur in all parts of the world. The process by which vegetation feedbacks create these patterns is a self-organizing or autogenic process. Consider two types of vegetation with opposite tolerances to some abiotic environmental factor, such as temperature, precipitation, or salinity. Then, only one of the vegetation types may occur at one end of the gradient (the best adapted to those conditions), and only the other vegetation type may occur at the other end of the gradient (the best adapted to those conditions). But over some intermediate range of the abiotic variable, there could be an area of potential overlap of the two vegetation types where, in principle, either of the two types of vegetation could occur. If these vegetation types compete strongly, a sharp boundary could form somewhere in that intermediate range by mechanisms discussed later. If there is no underlying environmental gradient, but alternative stable states are possible, then it is still possible for patchy, possibly irregular landscape pattern of the two vegetation types. The precise pattern developed would depend on various contingencies, such as disturbances, the way in which the vegetation types spread through seeds or vegetative propagation, and so forth (e.g., [8]). For example, if the underlying environment is homogeneous except for an elevation gradient, and water or nutrients are limiting, then it is possible for a regular landscape patterns of alternating stripes of either two vegetation types or one vegetation type and bare soil to emerge perpendicular to the downhill flow of water and nutrients to emerge [9]. These landscape patterns can also occur on a flat landscape, as long as there are mechanisms to redistribute the resources, through water movement, toward vegetation patches that are large enough to monopolize resources, producing long-distance negative effects on resource levels away from the patches $[10,11]$. Specific examples are discussed later. When the flow of water is overland and substantial enough to cause erosion and deposition of soil, the physical effect of water flow may be an important factor in the redistribution of materials and may create striped patterns of vegetation parallel to the water flow. The possible occurrence of these different vegetation patterns and their causes is summarized in Figure 1. This is meant only as a rough guide to the factors involved in these patterns. Later the detailed mechanisms underlying patterns in each of these categories in various ecosystems are discussed.

Understanding the factors creating and maintaining these sorts of spatial patterns, both the complex landscape patterns and ecotones, is critical for future management $[12,13]$ because these patterns can affect the functioning of the whole ecosystem. Climate change is already causing latitudinal and altitudinal shifts in ecosystems as a result of changes in temperature and precipitation over the past few decades, as reviewed by Walther et al. [14] and others. One question is whether such shifts in ecosystems will occur gradually, at the same pace as climate changes, or whether it will occur episodically, with large-scale changes occurring.

\section{Formation of Sharp Ecotones}

One striking feature of vegetation is the transitions, or ecotones, between vegetation of different types or species. Gosz [15] summarized a hierarchy of spatial scales on which such transitions could be viewed (see also [16]). At the biome scale, gradients in climate and topography are controlling factors (e.g., [17-20]), while at the landscape scale, gradients in weather, topography, and soil or edaphic characteristics determine vegetation patterns [21]. These gradients sometimes have specific attributes, creating "hydro-ecotones" or "chemo-ecotones", and so forth [22]. At the still smaller scale of the patch, variations in soil characteristics, microtopography, and microclimate, along with species interactions, are important factors [23]. Finally, at the scale of the dimensions of individual plants, intraand interspecific interactions, physiological controls, soil chemistry, soil fauna, and microclimatology all play roles.

The study of ecotones has a long history [24-27]. Ecotones usually occur along externally imposed environmental gradients, either as changes in edaphic characteristics, such as soil depth (e.g., [28]) and other soil properties, or climatic variables, such as temperature or precipitation (e.g., [29]). The role of plant physiology in ecotone formation was also recognized. The physiological adaptations of a given vegetation type or species determine how it will respond to a spatial gradient of a particular abiotic variable. For example, if its reproduction and growth rate increase and/or its mortality decreases with an increase in an environmental variable, then, ignoring effects of competing vegetation types, the biomass of that type or species can usually be expected to increase smoothly along an increasing gradient of that variable. If one other vegetation type occurs and 


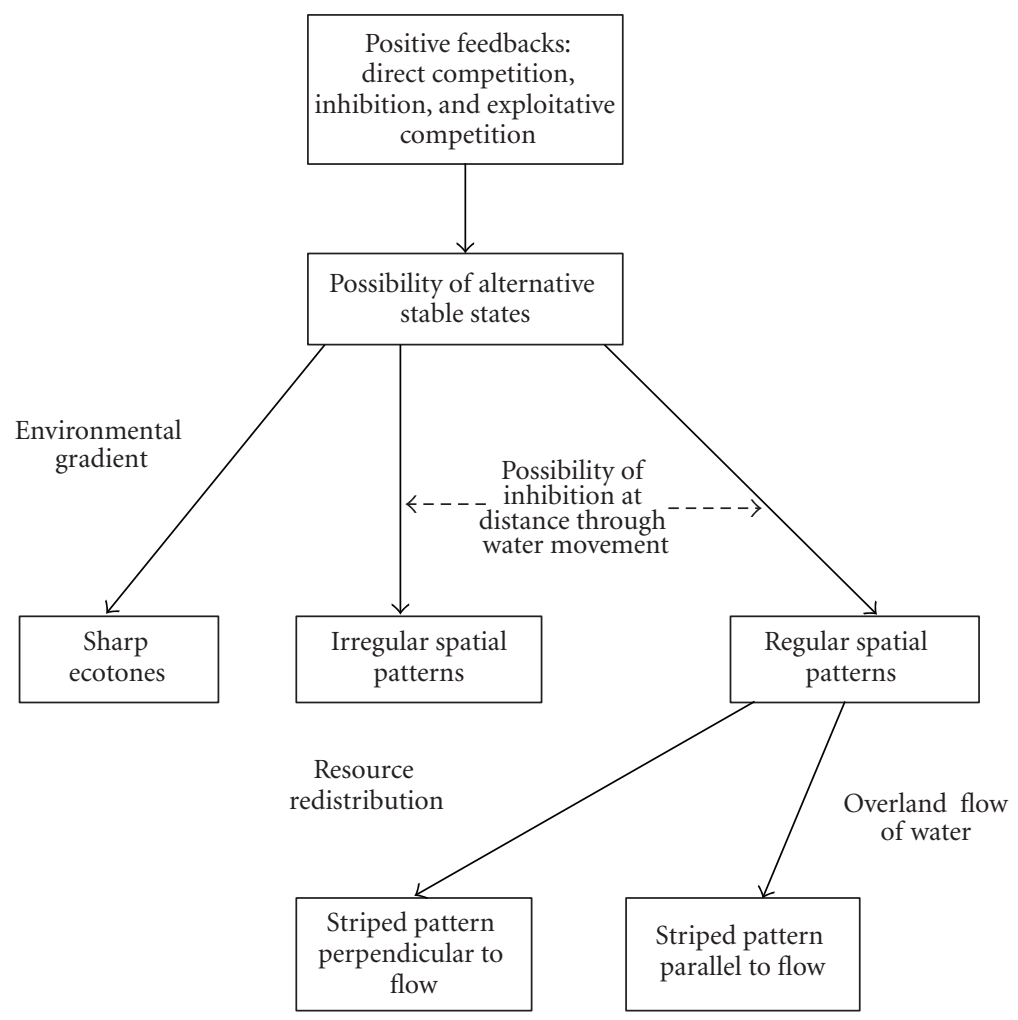

FIGURE 1: The schematic shows the types of spatial patterns that may form due to the possible occurrence of alternative stable states in an area. The boxes indicate different types of patterns that might emerge under the conditions indicated, under certain criteria. See text for description.

the other vegetation type responds oppositely to that abiotic gradient, then, in the absence of strong interactions between the two vegetation types, there should be a smooth transition, or ecotone, along the gradient in one direction, from dominance by one type to the other, with the biomass of one type approaching zero and the other approaching some maximum carrying capacity. This is the type of ecotone witnessed along many types of environmental gradients, in which each of the two types dominate at one end of the gradient but are interspersed in between [30-32]. These vegetation patterns that are determined purely by the underlying gradients in abiotic factors are defined as allogenic; that is, they are driven by external environmental factors alone. Abiotic factors usually vary gradually, so vegetation transitions are often gradual as well. Sharp changes in edaphic conditions, or even microclimatic conditions, can also occur, however, and vegetation change may be sharp as a consequence of the different vegetation types adapted to these different conditions $[33,34]$.

However, vegetation changes at the landscape scale are sometimes very sharp, sometimes almost discontinuous, even when the underlying gradient in environmental gradient is small or, in some cases, virtually nonexistent [35]. Part of the explanation for these sharp ecotones is that individual plants of these two different vegetation types or species may compete with each other more strongly than they do with plants of their own type or species. Thus, each type limits the other type and creates a sharper transition between types than would be explained by environmental gradients alone. Also, vegetation is not a passive slave of the abiotic environment but can dramatically alter the environment through building soil, stabilizing nutrient availability, moderating temperature, changing soil $\mathrm{pH}$, adding structure, and changing conditions in many other ways (e.g., [36]). This is well known to occur during the process of plant succession, in which there is a sequence of changing dominant plant types and/or species in a given place following a disturbance, for example, old-field succession following abandonment of a farm [37, 38]. This ability of vegetation to alter the environment can have spatial consequences as well because each vegetation type may alter environmental conditions in a way that favors itself over the other types of vegetation. The result may again be the formation of much sharper boundaries between two vegetation types than the gradual changes in the externally imposed environmental conditions.

The mechanism by which sharp boundaries between vegetation types can emerge has been termed a positive feedback "switch", in which each vegetation type alters the local environment through positive feedback in a way that favors itself $[39,40]$ and tends to exclude the other type. This positive feedback switch was first described to explain what is referred to as the forest/mire ecotone [39, 41]. This ecotone can exist in geographically widespread forested peatlands, although the authors' study site was in the western South 
Island of New Zealand. In this peatland, dense native forest can abruptly give way to pure mire vegetation with no obvious explanation in terms of exogenous environmental gradients, and the sharp ecotones between these types appear to be stable. Although it is difficult to determine the exact cause of the initial formation of these ecotones between patches of different vegetation type, the authors were able to provide an explanation for their stability. Mire sites are very low in the nutrients nitrogen, phosphorus, and potassium, so that tree seedlings that fall in the mire cannot establish; the low nutrients act as an inhibitor to woody vegetation. Tree seedlings can establish, however, on the boles of fallen trees, which have sufficient nutrients for seedling survival. Trees seldom fall outward into the mire because the strong wind gusts that topple tree tend to come from the mire side of the ecotone, and they push the tree boles away from the mire, which tends to prevent extension of the forest into the mire. The forest end of the ecotone is able to resist encroachment by the mire because the fallen logs provide a raised surface above the mire. Thus, both the mire and forest maintain themselves, separated by a sharp stable ecotone. The mire and forest actually represent alternative stable states, as either could occur on a given area of land, and the current boundaries between the two types depend on some initial, perhaps chance, conditions, even in the absence of a preexisting environmental gradient. This situation is bistable, and is an example of switching behavior that is the basis for a number of other vegetation patterns discussed later. Each vegetation type interacts with its local environment to provide conditions that are favorable to itself and inhospitable to the other vegetation types, the mire vegetation, by providing no suitable places for the tree seedlings to survive, and the forest vegetation, by providing sites on boles that are above the level of the mire and on which sufficient nutrients occur. These can be interpreted as positive feedbacks of each vegetation type on itself, leading to negative feedbacks on the other vegetation type.

Another sharp ecotone characteristic of bog ecotones is that between Sphagnum moss and vascular plants [42, 43]. These two vegetation types compete indirectly due to feedbacks that each vegetation type has on soil conditions. Sphagnum moss creates organic acids when it decomposes that lower the $\mathrm{pH}$ to levels that vascular plants cannot tolerate and also tend to create locally saturated soil moisture conditions and accumulations of peat that isolate upper layers of soil from mineral nutrients. This positive feedback between Sphagnum and soil properties favors itself by inhibiting vascular plants. Vascular plants may be able to resist the spread of Sphagnum if their local soil conditions are richer in nutrients, and local recycling of nutrients from dead plants can help maintain favorable soil conditions. The sharp vegetation boundary seems to emerge concomitantly with a sharp gradient in $\mathrm{pH}$ and soil moisture conditions through the positive feedbacks.

In coastal zones, as well as inland areas where salt pans exist, sharp ecotones may be maintained between halophytic (salinity-tolerant) and glycophytic (salinity-intolerant) vegetation (e.g., [44-50]). This appears again to be a case where positive feedbacks between each vegetation type and certain abiotic conditions create the boundary. In the Greater Everglades region of southern Florida, for example, mangrove communities and tropical hammock communities (the latter having species such as Quercus virginiana, Lysiloma bahamensis, Bursera simaruba, etc.) can occupy overlapping ranges on the landscape [51, 52]. The hardwood hammocks are restricted to areas with salinities below 7 psu, but mangroves are able to tolerate a wide range of salinities $[47,53-55]$, so they can compete for space with the hardwood hammock species. Typically, mangrove and hardwood hammock trees are not interspersed, but rather sharp boundaries exist between uniform stands of the two vegetation types. The vadose (unsaturated soil) zone salinity level decreases sharply across the boundary from salttolerant to salt-intolerant vegetation. Hardwood hammock species tend to occupy higher elevations, but the differences in elevation between hammocks and mangrove vegetation are slight, and the salinity of the externally imposed brackish groundwater decreases very little from areas occupied by mangroves to areas occupied by hammock communities. Although factors such as mean tidal height play a role in determining the ecotone [56], it is not initially clear why both sharp ecotones in vegetation and in vadose zone salinity exist as they do.

The puzzling observation of this sharp ecotone between mangrove and hammock vegetation led Sternberg et al. [47] to propose that feedback effects of the two vegetation types on local soil salinity maintain the sharp ecotone. Hardwood hammock species are competitively superior in low salinity areas, suggesting that halophytic species will usually be excluded from areas farther from tidal influence by competitive exclusion [57-59]. However, mangrove vegetation, once established, can influence vadose zone salinity in its favor. Both mangroves and hammock species obtain their water from the vadose zone. In those coastal areas, the vadose zone is underlain by highly brackish groundwater, so that evapotranspiration, by depleting water in the vadose zone during the dry season, can lead to infiltration by more saline groundwater. Although hardwood hammock trees tend to decrease their evapotranspiration when vadose zone salinities begin to increase, thus limiting the salinization of the local vadose zone, mangroves can continue to transpire at higher salinities [60-62]. Therefore, each vegetation type promotes local salinity conditions that favor itself in competition, which helps to explain the stability of sharp boundaries between the vegetation types and the vadose zone salinity (Figure 2 ). The ability of halophyteglycophyte interactions to form a sharp ecotone has been described by both spatially explicit simulation models [4749] and a simple spatially implicit mathematical model [50] with two vegetation types and salinity as variables. The three-variable model used by Jiang [50], containing two competing vegetation types and an abiotic variable, is typical of other ecotone models, such as that of Accatino et al. [63] (described afterwards), who use the variables tree biomass, grass biomass, and soil moisture to model savanna dynamics as functions of precipitation and fire frequency, indicating that this type of simple model has some generality as a model of maintenance of a sharp ecotone. 


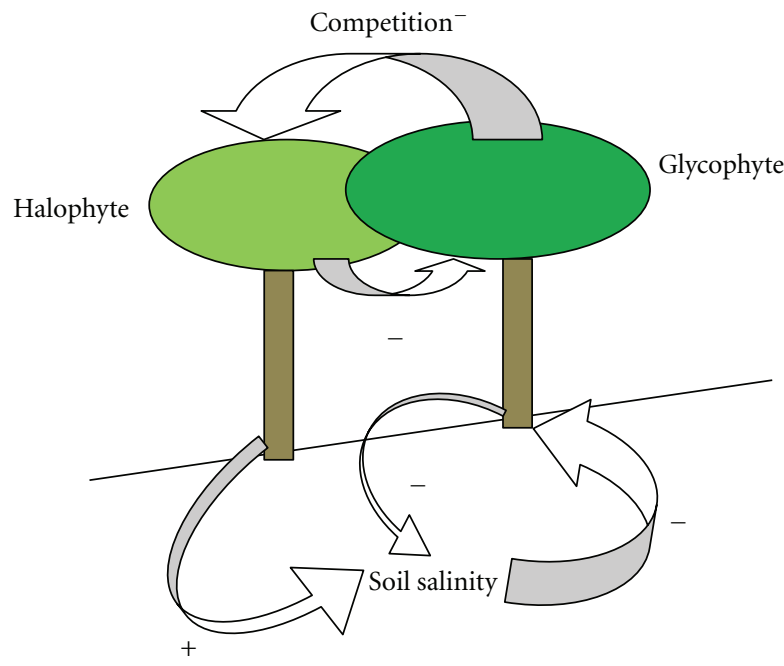

FIGURE 2: Feedbacks between halophytic and glycophytic vegetations. The halophyte has a positive effect on soil salinity, which has a negative effect on glycophyte growth. The glycophyte is assumed to be a superior competitor for light.

Edaphic conditions such as nutrients, $\mathrm{pH}$, and salinity underlie the sharp ecotones described in the previous examples. However, short-term disturbances, such as fires and wind, acting as inhibitors, can also participate in maintaining a sharp boundary along an environmental gradient. The importance of fire on a regional spatial scale was long recognized in affecting the boundaries between grassland and woodland, or between two woody types of vegetation [64], usually differing in flammability. On such a spatial scale, the transition from forest to grassland occurs along a gradient of decreasing rainfall. Transeau's [65] classic paper "The prairie peninsula" argued convincingly that fire played a role in maintaining tallgrass prairies in climatic zones that would favor deciduous woody vegetation. Slow-growing trees are unable to recover from frequent fires, whereas prairie grasses could revive in a year. In the absence of fire, in many areas, the forest tends to spread, moving the ecotone into the grassland (e.g., [66]).

On the landscape scale, a gradient in the depth of the water table from the surface can also affect vegetation and susceptibility to fire [67]. Boughton et al. [68] studied the ecotones between different vegetation types, rosemary scrub, scrubby flatwoods, and flatwoods in Florida shrublands along elevation gradients. Both elevation (which generally relates here to distance to water table) and time since last fire influence the three types of vegetation. Time since last fire also affects the sharpness of the boundaries between these types; the ecotone becomes more diffuse the longer the time since the last fire. An explanation is that the vegetation types differ in flammability and resistance to mortality from fire. Fires reduce the dispersal of the vegetation types that would tend to blur the ecotone. A similar mechanism was found by Vilà et al. [69] in studying the switches between the alternative vegetation types of shrubs and tussock grass, Ampelodesmos. The tussock grass is highly flammable but suffers only low mortality under fires. Tussock grass would be outcompeted by the later successional shrub (and eventually pine) species, so the ecotone shifts in the favor of the latter in the absence of fire, but the periodic fires that Ampelodesmos favors maintain a relatively sharp boundary. Such selfreinforcing mechanisms due to greater flammability also exist in sclerophyll vegetation, which is able to maintain community stability against forest vegetation in areas studied in the Klamath Mountains of California [70].

Although fire events are discrete rather than continuous variables, models designed for longtime scales can incorporate average fire frequency. Accatino et al. [63] used a spatially implicit model of two competing vegetation types, trees and grass, along a precipitation, $p$, gradient. Tree biomass, $T$, grass biomass, $G$, and soil moisture, $S$, are the variables, with the soil moisture responding to precipitation, evaporation, and evapotranspiration. Soil moisture is positively affected by precipitation, so along a gradient of increasing precipitation, conditions favorable to trees gradually increase. However, the existence of fire makes the dynamics more complicated, with the possibility of alternative stable states. Both trees and grass are negatively affected by fire in the model. But because grass biomass is necessary for fire to occur in the model, the loss rate of trees to fire was represented as a product of tree and grass biomass, $-f \delta_{F} G T$, where $f$ represents fire frequency and $\delta_{F}$ the effect of fire on tree mortality, whereas the negative effect of fire on grass was a function of grass biomass alone, $-f G$. Thus, high grass biomass can suppress trees if grass biomass can become large enough to promote frequent fires. Trees tend to favor themselves by shading grass [71], so that sufficiently high tree biomass can suppress grass and become virtually invulnerable to suppression through fires. A major difference between grass and tree is in the growth rate, which was of the order of tens to hundreds of times faster for the former. This slow growth rate of trees means that a fairly spatially constant boundary can be maintained by fires with a return interval of a few years. The authors used bifurcation analysis to study the model along gradients of $f$ and $p$. They found some 
zones where a mixture of grass and trees (savanna) could occur, but also regions of bistability, where alternate stable states of pure grassland or pure forest could occur. In these regions of bistability, the grassland and woody vegetation tend to be separated by sharp ecotones. For example, the establishment of woody vegetation can provide a site safe from fire where tree seedlings can germinate and grass is excluded [72]. Although tree-grass interactions are much more complex than a simple model can represent, the model supports the idea of bistability and consequent formations of sharp ecotones (see also [73]). This model could even be extended to include the effects of grazing, which would be expected to decrease grass biomass and fire frequency, with consequences for the location of the ecotone (e.g., $[74,75]$ ).

Staver et al. [76] have also modeled the ecotone dynamics of trees and grass, showing that fire creates the possibility of observed sharp boundaries between the states of trees and savanna (mixed trees and grass). Those authors chose as variables fraction of land cover by adult trees, saplings, and grass. Fire is incorporated in the model through assuming that the recruitment of saplings to large trees is inhibited by fire, the frequency of which depends on the fraction of grass in the area. The model of Staver et al. [76] is based on data at the continental of Africa on vegetation cover and rainfall, so the conclusion that alternative stable states can occur has substantial support from data.

Altitudinal zonation of vegetation has been the subject of much study partly because altitudinal climate gradients are much sharper than latitudinal gradients, and thus altitudinal ecotones are easier to study. Using an individual-based simulation model (FORET), Shugart et al. [77] simulated a beech-to-yellow poplar transition along elevational gradients of both mean annual temperature and growing degree days. They showed that a sharp transition occurred from American beech (Fagus grandifolia) to yellow poplar (Liriodendron tulipifera) as either of these factors increased (thus from higher to lower elevation). The competition for light between the two species played a role, with the beech having an advantage in that respect, but the faster growth rate of yellow poplar at lower elevations allowed it to outgrow the beech in that zone. They showed that in simulations a property of alternative stable states, hysteresis, occurred; that is, once one vegetation type was established, a large change in temperature was needed to reestablish the other type. Yamamura [78] had already shown mathematically the hysteresis property of sharp boundary formation using a Lotka-Volterra competition equation model. More recently, ecotone models, such as treeline models [79-81], have simulated complex positive feedback along smooth environmental gradients, in which competition is included, and have shown that sharp ecotones can result.

The alpine treeline marks the altitudinal limit of tree growth and is characterized by an ecotone from upright closed canopy forest to tundra $[82,83]$. This can be abrupt or gradual, in the latter case transitioning through dwarfed trees and krummholz [84]. Temperature is a major factor in determining the treeline [85]. Also, wind can be a negative factor on seedling and tree survival, so it acts as an inhibitor to trees moving upwards into tundra-dominated areas. However, trees occurring in groups act to shelter each other, which is a form of positive feedback that can stabilize the tree line against being pushed downward by high winds [86]. Alftine and Malanson [84] in their study of the treeline on Lee Ridge, Glacier National Park, Montana, showed that there is also a net directionality of the wind there, which means that the positive feedback can be directional. A seedling has a higher chance of survival in an area of land that is slightly downwind (within a meter or so) of a tree. When those authors built that effect into a simulation model, they were able to explain much of the structure of the treeline ecotone on Lee Ridge. Malanson et al. [80] also noted other positive feedbacks by which trees could improve conditions in their favor. These include increasing fine soil component and therefore water holding capacity, increasing organic matter and nutrients, and increasing soil moisture by trapping snow. The authors suggested that these positive feedbacks were necessary to produce the observed ecotone patterns, which include existence of large patches and fingering into the tundra rather than simply a linear boundary (see also [87]).

Even at the lower altitude ecotones between two tree species, wind can sometimes serve the purpose in maintaining sharp zonation. In the study of the boundary between subalpine tree types, fir (Abies sachalinensis) and spruce (Picea glehnii) in Japan, it was found that there is generally a trend in canopy replacement of the latter by the shadetolerant former species. However, the authors, Nishimura and Kohyama [88], found that extreme wind disturbances could break the stems of the older P. glehnii, leaving a pure stand of understory $A$. sachalinensis, leading to a sharper ecotone than would occur if succession alone occurred. Fire can be a similar factor in helping to maintain a boundary between two tree types. In the tropical forest of the Cordillera Central of Hispaniola, a cloud forest occurs below $2000 \mathrm{~m}$, while pine forest dominates above that altitude [89]. The cloud forest is physiologically capable of spreading to higher elevations, but frequent fires tend to prevent such spread. There is a limit to the downward spread of fires both because of a fairly sharp abiotic discontinuity-the tradewind inversion leads to higher moisture below about 1900$2000 \mathrm{~m}$ - and because of the nature of the cloud forest vegetation itself, which has high moisture content. Hence, the abiotic discontinuity provides the basis for the sharp ecotone, but the properties of the vegetation related to fire sharpen it.

Bader et al. [79] modeled alpine treeline dynamics in the tropical zone; the upper montane cloud forest and páramo. The treeline dynamics in this tropical alpine zone, while not experiencing as severe cold conditions as in the temperate and boreal zones, is affected by nightly frosts. It is also affected by intense radiation which can cause photoinhibition, as well as by fire. The fires start in the páramo and can kill young trees that are invading. Two positive feedbacks affect the ecotone. First, a high density of trees provides mutual shading, which reduces photoinhibition and thus enhances photosynthesis. Second, high tree cover reduces páramo vegetation, which reduces the frequency and intensity of fire. The authors showed in a simulation model that these two factors had the net effect of sharpening the ecotone. 
Sand dunes are examples of ecosystems on which alternative stable states can exist $[90,91]$. Cases of sharp ecotones between alternative stable states have been studied in dune slacks, low-lying areas between the foredunes and the main dunes [92]. In these dune slacks, species of different successional types, such as early successional Littorella uniflora and later successional Carex nigra, can coexist in close proximity with sharp boundaries between them. Each species can have positive feedback with their local environment that makes it more favorable to itself. L. uniflora releases oxygen from its roots, which causes phosphorus precipitation as iron phosphate, limiting the growth of $C$. nigra and other later successional species. C. nigra tends to enhance available phosphorus, favoring itself.

The previous examples include vegetation types making use of inhibitors already occurring in the environment in competition with other vegetation types. However, plants may produce their own inhibitors as well. The term allelopathy describes the use by one organism of biochemicals to have either negative or positive effects on other organisms. Of interest here is the use by plants of chemicals that can retard or kill competing plants. This might have a similar effect to the promotion of soil salinity by mangroves in inhibiting hardwood hammock tree growth, in which case somewhat analogous models could be used to describe spatial competition [93]. Empirical studies have shown that the effect of allelopathic chemicals can create vegetation zonation; for example, the effect of phenolic acids from chaparral vegetation on grasses $[94,95]$ is to slow the growth of or kill other organisms. Likewise, in Florida, sharp ecotones exist between sandhill and pine scrub communities, at least in part due to allelopathy from scrub vegetation [96]. In Australia, a woody invader, Lantana camara, produces allelochemicals [97]. It is able to form thickets that exclude native trees in the immediate vicinity. The study of the role of allelopathy in species competition is still in an early stage, however, and thus its role in maintaining sharp ecotones, relative to other factors, such as fire and resource competition, is not known with certainty yet.

Alternative stable states from positive feedbacks are hypothesized to be the basis for the existence of "tree islands" that dot the landscapes of freshwater marshes such as the Everglades [52, 98], Okefenokee Swamp, the Pantanal wetland in Brazil [99], the Okavango delta, Botswana [100], the wetlands of northern Belize [101], and boreal bogs [102-104]. These tree islands are slightly higher in elevation than the surrounding marsh, from which they are separated by sharp ecotones. They are also more productive and have much higher concentrations of nutrients, particularly phosphorus, in their soil than the oligotrophic marsh. Wetzel et al. [105] and D'Odorico et al. [106] have proposed that positive feedback sustains this bistable landscape. Slight irregularities in elevations on the landscape may have been the initiators of small islands of relatively high productivity because of less negative effects of flooding. But the higher productivity is amplified by one or more of the following positive feedbacks: (1) tree islands have higher evapotranspiration than the surrounding marsh and thereby pull in water and phosphorus from the surrounding marsh
$[107,108],(2)$ tree islands can serve as nesting places for colonial wading birds, which deposit nutrients (in guano) gained from foraging in the marsh (e.g., [109]), and (3) by projecting above the surrounding marsh, tree islands might also be able to capture relatively more airborne nutrients as dry deposition [110]. All three processes might plausibly be expected to capture new nutrients from external sources at rates positively related to the amount of standing crop biomass of the tree island. Each of these mechanisms would cause an increase in nutrient input that is positively related to the standing crop of vegetation biomass, consistent with the self-organizing processes discussed by Rietkerk et al. [111] and Givnish et al. [112]. This biomass density-dependent external input does not lead to endlessly growing biomass in such locations because diffusion and other loss processes eventually balance the biologically driven fluxes. However, these mechanisms do lead to sustained inhomogeneities in the distribution of nutrients and vegetation over the landscape. Grass is excluded from the tree islands by shading, while the spread of tree islands is probably largely resisted by frequent marsh fires. Thus these tree islands have been stable over many centuries, although anthropogenic changes in hydrology, such as flooding, have led to the loss of many during the past few decades [52].

Erosion is another inhibiting factor which occurs in aquatic and marine environments. Erosion may separate two vegetation types, or may separate vegetation from unvegetated soil or sediment. Both types of situations have been found in which the two states are alternative stable states and are separated by a sharp ecotone. Walker et al. [113] noted a sharp boundary between rush (Salicornia quinqueflora) vegetation and mangrove vegetation along a coastal transect, where erosion was much higher on the mangrove side, while rush, if able to build up high biomass, could resist erosion. Van Wesenbeeck et al. [114] studied patches of Spartina anglica on an intertidal flat in the Netherlands, which occur as dense tussocks. These patches, however, are not very stable and can easily switch to the alternative state of unvegetated sediment. Van de Koppell et al. [115] showed the existence of alternative stable states on tidal flats. Areas occupied by diatom can build up silt that has a positive feedback on diatom growth and resists erosion. The result is sharp ecotones between the vegetated areas and areas eroded down to sediment. Carr et al. [116] noted sharp boundaries between seagrasses and bare sediment along a depth gradient. They showed that bistability existed, with the seagrasses able to form beds that could resist erosion by slowing water flow locally.

Each of the previous ecotones can form along environmental gradients, as long as there is a zone along which alternative steady states can occur. These fall into the "sharp ecotone" category of Figure 1. What happens if there is no environmental gradient (or only a very slight one) and the alternative stable state zone covers a large area? In this case, if the vegetation types are able to move through dispersal, and if disturbances create gaps in which each vegetation type can colonize and grow, patchy or irregular patterns may emerge. Following a disturbance that clears an area, either vegetation type may be able to colonize first and 
grow, excluding the other type, until it is eventually removed by another disturbance. Jiang et al. [49] used agent-based modeling to simulate the mangrove-hardwood hammock interaction both in the presence and absence of an externally imposed gradient in salinity input caused by tidal effects. In the presence of these effects, the combination of salinity gradient and vegetation positive feedback created a sharp boundary (Figure 3(a)). In the absence of a salinity gradient, the positive feedbacks can still maintain patchily distributed mixtures of the two vegetation types (Figure 3(b)). The patterns created are irregular and so correspond to a type of "irregular spatial patterns" denoted in Figure 1. These patterns occurred through the random initial distribution of seedlings. Creation of regular patterns in space requires at least the addition of longer range negative effects that can suppress vegetation at a distance, which are not present in the model of Jiang et al. [49].

\section{Resilience of Ecotones to Disturbances}

In all of the previous examples, there exist zones along the environmental gradient on which either of two stable alternative vegetation states can occur. The ecotone merely represents the current position of the sharp boundary within this area of overlap, created by the positive feedbacks of each vegetation type favoring itself and excluding the other. Because this overlap area is a zone of bistability, it is possible that either when gradually changing environmental conditions reach a certain threshold point or when a disturbance occurs that is large enough to push the current state into the domain of attraction of an alternative state, a rapid regime shift could occur; that is, there could be a sudden, spatially extensive change in favor of one of the alternative vegetation types that shifts the position of the ecotone (e.g., [117-119]). The reason that regime shifts can be sudden stems from the fact that the shift is from one alterative stable state of the bistable situation to the other alternative stable state. A regime shift can be spatially extensive if the region of bistability of two competing vegetation types is large. Because of these self-reinforcing positive feedbacks, the ecotone can resist change until the change in the environment is great enough to overcome the feedbacks. That is termed "resilience." But once the resilience of the self-reinforcing feedbacks is overcome by external forces, the feedback cycles operate in the opposite way to promote change to the alternative vegetation type.

One of the great concerns related to climate change is how ecosystems, including vegetation patterns, across the globe will respond. Changes in means and extremes of temperature and precipitation, sea level rise, and changes in frequency and intensity of storms and storm surges, as well as many other consequences of climate change, may alter the fitness of vegetation types in their current locations. This will likely destabilize the current geography of ecosystems and is already doing so in places. Ecotones are places where the effects of climate changes are most likely to be evident [120]. As environmental factors change, some of the ecotones described previously will be of special interest. One response of these ecotones may be simply a gradual changing of spatial position as the temperature and precipitation change, fire regimes changes, or groundwater salinity encroaches. However, these ecotones are stabilized in part through feedbacks that in many cases separate alternative stable states. These feedbacks will continue to act in favor of maintaining the vegetation patterns, even as external environmental conditions change, and they may resist the externally imposed changes, at least up to some point. If vegetation states along ecotones are alternative stable states, they might not simply move gradually in response to a temporally changing environment, but instead, there could be sudden changes in which an ecotone breaks up and reestablishes again far from its original location [120]. Holling [121] introduced the concept of "resilience" to ecology describing the ability of a stable state to resist the effects of external changes in causing such a flip from one state to another to occur; that is, resilience is "the capacity of ecosystems to resist and adapt to such stress without switching to a state characterized by a different set of structuring processes is called the "adaptive capacity" [122]." Resilience can be measured by the magnitude of disturbance that can be absorbed before the system changes its structure. In the 1970s catastrophe theory was developed to describe the way that systems can flip suddenly from one state to another when slow changes in parameters reach thresholds. Studies by Scheffer et al. [123] and Scheffer [124] showed convincingly that shallow lakes could switch between two extreme states: one dominated by aquatic macrophytes and one dominated by phytoplankton. This switch can be promoted by temperature change. The reason that dramatic changes in the ecosystem can occur is that there are "selfreinforcing" processes occurring within an ecological system, like a lake, that tend to maintain it in a stable state. But if the system is pushed too far, those self-reinforcing processes break down and turn against the original system.

Two types of environmental change can trigger regime shift (e.g., $[119,125])$. One is gradual change in some environmental variable that eventually reaches a threshold past which the shift occurs (e.g., [117, 126-128]). The second type of change is a large disturbance that pushes the system beyond a threshold, such that it cannot return to the original stable vegetation state, but moves to the alternative stable state (e.g., [129]). If the disturbance is not so large that it pushes the system outside its domain of ecological resilience, the ecosystem can return to its original state following a disturbance [121]. However, when a disturbance pushes the system beyond a certain threshold, the ecological resilience of its initial stable state is exceeded, and the system moves to an alternative stable state $[6,18]$. Disturbances can be of many types as previously noted. Besides natural events such as droughts freezes, hurricanes, and storm surges, they may include anthropogenic causes, such as fire suppression and increases in grazing [75]. Determining the thresholds at which such regime changes may occur is a challenge to ecology and related sciences $[12,13]$. There do not appear to be many attempts to estimate the resilience of ecotones to disturbances. One that could be mentioned involves the mangrove-hardwood hammock ecotone model 


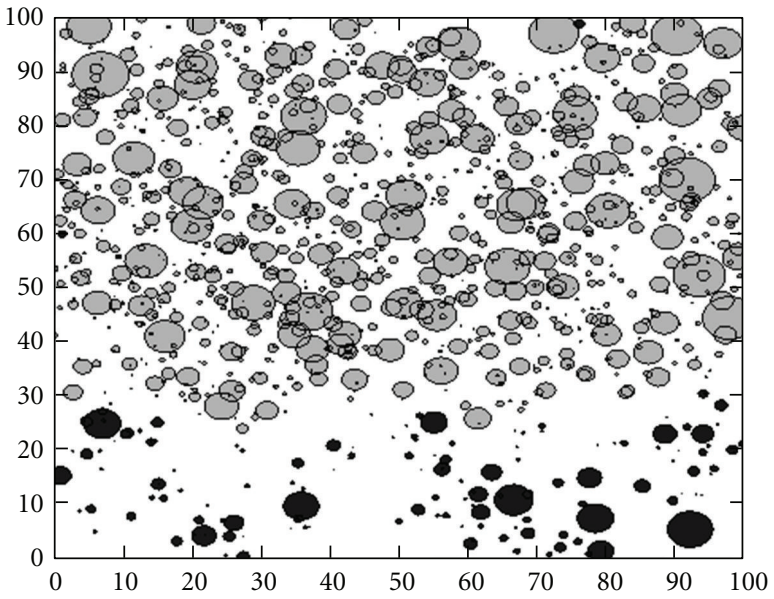

(a)

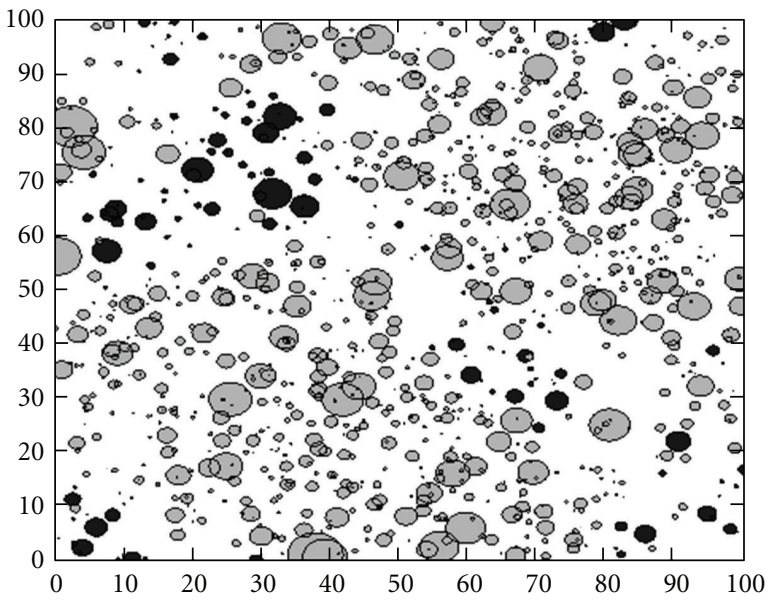

(b)

FIGURE 3: Simulation output showing distribution of mangrove (dark) and hardwood hammocks on a $100 \times 100 \mathrm{~m}^{2}$ model landscape. (a) Simulation with both spatial gradients in salinity input due to tides. (b) Simulation in which there is no environmental gradient of salinity input; the groundwater salinity is such that alternative stable states can occur over the whole area (from [44]).

that was considered earlier. Jiang [50] considered the possibility that feedbacks maintaining the ecotone could also be overwhelmed by a disturbance, so that the system is pushed towards an alternative stable state; that is, the original ecotone would be broken up and reestablished in another place, with a large area transforming from one stable state to another. For the mangrove-hardwood hammock ecotone, this disturbance could be a sharp upward pulse in soil salinity due to storm surge overwash of an area initially dominated by hardwood hammock. By reducing hardwood tree growth and bringing a flood of mangrove seedlings, the surge may lead to a positive feedback cycle of increasing salinity and increasing mangrove biomass growth. This could lead to rapid large-scale inland expansion of mangroves. Simulations by Jiang [50] indicated that in order for a regime shift to occur in their model, soil salinity would have to be held at high levels for a few years, and large inputs of mangrove seedlings would also be necessary. How likely such a large event is requires further research (see also [130] for a discussion of seed input with respect to movement of the alpine treeline and [131] for mangrove seedling dispersal across a mangrove salt-marsh ecotone).

Resilience modeling as in Jiang [50] may be useful for projecting possible changes in the vegetation of low-lying coastal regions, where rising sea level is leading to greater vulnerability of coastal vegetation to storm surges from hurricanes. While the model results here are hypothetical, changes towards salinity-tolerant vegetation have been noted in experimental studies on salinity inundation [132]. Also, observations of coastal areas of Louisiana following hurricanes Katrina and Rita in 2005, which created storm surges affecting the coastal areas of Louisiana, have identified changes towards more salinity-tolerant vegetation [133]. Therefore, modeling is needed to anticipate future changes to coastal ecotones and to other ecotones that may be vulnerable to climate change. I know no attempts to quantify resilience so far, but empirical evidence of changes might be used to estimate resilience of some ecotones. For example, reduction of fire frequency is a disturbance that can lead to rapid increase in tree invasion of grassland $[66,72]$, and there may be some threshold fire frequency below which the ecotone will shift.

\section{Landscape Vegetation Patterns in Terrestrial Ecosystems}

The self-organizing patterns reviewed afterwards differ in some ways from the previous sharp ecotones. The latter typically involve two vegetation species competing along a gradient in some abiotic factor, forming a narrow boundary zone. Examples of the former type of pattern that have been studied in detail can occur in the absence of any underlying gradient, but they require movement of water to redistribute resources on the landscape. This movement of water can lead to competitive effects at a distance, as vegetation in one part of a landscape can use scarce water and/or nutrient resources and thus deny them to vegetation in another part. The former type of patterns does not necessarily require different competing vegetation types but can involve vegetation of one species or assemblage alternating with bare soil in repeating patterns over a two-dimensional space, rather than a single narrow zone. What these two types of spatial phenomena, ecotones, and landscape vegetation patterns have in common is that they each generate spontaneously from positive feedbacks between vegetation and an abiotic environmental variable, creating alternative stable states.

A large body of theory has now been developed to explain these patterns of self-organization. Self-organization of structures in the environment is a process that has been studied in both physical systems (e.g., [134]) and biological systems. "In biological systems self-organization is a process in which pattern at the global level of a system emerges 
solely from numerous interactions among the lower-level components of the system. Moreover, the rules specifying interactions among the system's components are executed using only local information, without reference to the global pattern" [135]. Self-organization means that the pattern arises from processes within the system, not directly imposed by externally forces, although external forces create the conditions that lead to the pattern formation. Alan Turing showed through a mathematical analog how such patterns could form during embryogenesis, or the development of organisms [136]. An organism starts from a single cell and through cell division becomes a tissue consisting of many identical cells. The question is how these initially identical cells differentiate to form the spatial segmentation patterns that eventually become the different parts of the developing organism. As described by Camazine et al. [135], one of the models based on Turing's work (see [137]) involves the interaction of two chemicals that are produced in the system, a substrate $S$ and an activator $A$. The activator, $A$, autocatalyzes the formation of itself and uses the substrate (or resource). Both $A$ and $S$ decay in time and diffuse through space, with $S$ diffusing faster than $A$. Mathematical models of this process [137-139] show that over time a steady state pattern of peaks and valleys of $A$ and $S$ can be formed around the initial perturbation.

The previous example is an abstract mathematical model of activator and substrate. But it contains basic elements that can apply to a whole spectrum of self-organizing processes at spatial scales from the cell to the ecosystem. It contains the elements of autocatalysis, which is a positive feedback, and depletion, which is a negative feedback. In addition to feedbacks, some sort of movement in space is also needed, such as diffusion, though advection is also needed to explain some vegetation patterns. In addition, random perturbations are needed to disturb the initially homogeneous system away from a spatially homogeneous steady state. These are all universal elements in the self-organizing process. The specific physical and biological mechanisms can differ between actual situations.

Applications of versions of the Turing model have been made to several areas of ecology $[140,141]$. The examples of self-organization reviewed by Camazine et al. [135] mostly involve animals or microbes, but spatial vegetation patterns that involve analogous self-organizing processes are also well known. The recognition of regular vegetation patterns in certain ecosystem accelerated with the spread of aerial photography and satellite imagery. Vegetation patterns have been recognized, particularly in semiarid regions including parts of Africa, Australia, and North America and wetlands, such as peat bogs in Asia and North America. A vital area of ecology in recent years has been the modeling of the emergence of the observed patterns. Simulation modeling has confirmed the hypotheses that many regularly patterned landscapes are governed by some version of scale-dependent feedback, meaning that organisms grouped in patches modify their environment such that environmental factors have a positive effect on their growth at short distances (i.e., local facilitation) but a negative effect on their growth at long distances (i.e., large-scale inhibition). Patterns can be created by mechanisms of water flow, nutrient transport, and vegetation growth. "Self-reinforcing" processes occur on the landscape, which tend to maintain it in a stable state. But changing the external conditions, or perturbing them, might cause those self-reinforcing processes to break down such that the pattern is changed or destroyed. That is, as in the case of ecotones, the resilience of these patterns may be overcome.

4.1. Semiarid Land Hillslopes. Vegetation patterns are found in many semiarid regions, often occurring on hillsides, where stripes of vegetation alternate with patches of bare ground along parallel elevation contours. A famous example is the so-called "tiger bush" first reported by Macfadyen [2] in parts of Africa. Vegetation stripes form under conditions of low rainfall, gentle slope, and on soil on which the occurrence of plants increases water infiltration. Water runs off soil that is not occupied by plants but is absorbed on soil where plants are established. The plant community composition varies, consisting of grasses in some locations and shrubs and trees in others.

Imagine precipitation falling evenly along a hillside. If the surface is hard, water does not infiltrate but flows downhill accumulating in amount as it flows. However, if a small patch of vegetation happens to develop at some point along the slope, it will intercept some water, which will soak in and support further growth of the plant biomass, which will evapotranspire. The plant biomass at that point will ultimately reach a point that exhausts the water flowing from upslope and will grow no further. Below this point, there is no vegetation until enough flowing water accumulates from the precipitation intercepted downhill of the original point. At that new point, which is some distance below the first one, it is possible for a new vegetation patch to occur if seeds by chance are deposited there. This process can repeat itself again and again down the slope. The point patches can expand laterally into parallel stripes, forming the observed pattern of vegetation stripes. In a real situation, this regular pattern emerges from initially homogeneous bare soil on which small patches of vegetation become randomly scattered through seed dispersal. The initially tiny patches of vegetation emerge at these different random locations along the slope. Water flows down the slope. As long as the water is not infiltrating into the ground or evaporating, its flow accumulates downslope, assuming that precipitation is falling evenly along the slope. If the flowing water encounters a patch of vegetation, some of it will soak in the soil local to the plants and support the further growth of that patch. This will decrease the flow of water farther downhill from that location. Overall, some patches will be reinforced by water and will grow larger. Others, which are too close to upstream patches, and thus are deprived of water, will die out; that is, long distance inhibition occurs. Patches that are successful will grow until they capture all the water that impinges from upstream. They will grow laterally to form stripes that have regular distances between them, at distance intervals such that enough water accumulates from precipitation between stripes to maintain the downstream stripes (Figure 4). This pattern is not static. The stripes slowly move uphill because 


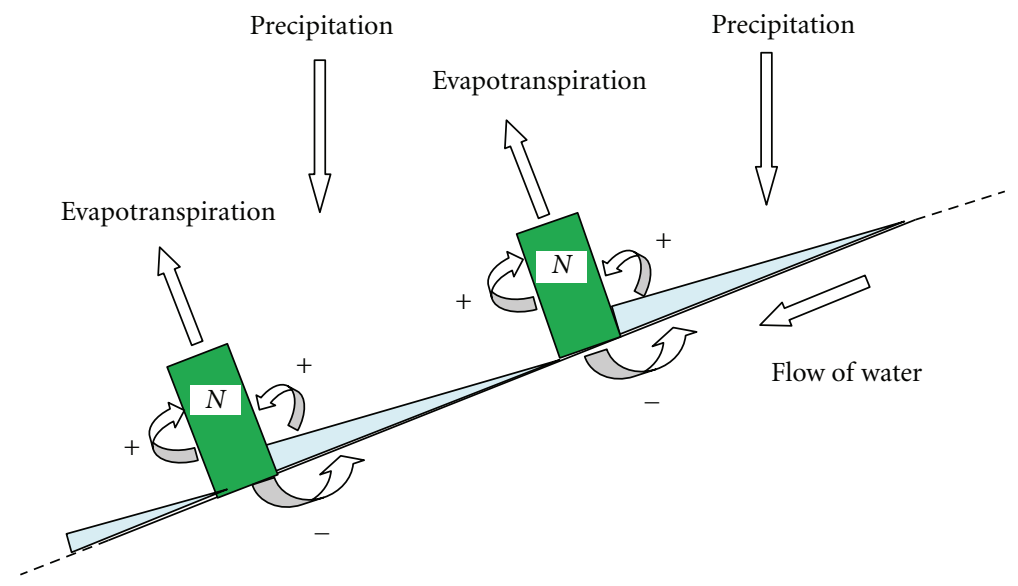

FIGURE 4: Stripes of vegetation are represented along a hillslope, as modeled in (1) and (2). Mean precipitation is assumed evenly distributed along the hillslope and to run down over a nonabsorbent surface until it reaches a vegetation stripe, where it is absorbed and evapotranspired. The vegetation stripes are evenly spaced.

colonization of bare areas can occur only at the moister uphill side of the stripe [142], and because plants on the downhill side of the stripe die as a result of inadequate water.

This situation has the subject of a number of models, including that of Klausmeier [9] who used a pair of partial differential equations for water $(W)$ and plant biomass $(N)$, defined on an infinite two-dimensional domain indexed by $X$ and $Y$. The equations for surface water and plant biomass are

$$
\begin{gathered}
\frac{\partial W}{d T}=A-L * W-R * G(W) * F(N) N+V \frac{\partial W}{\partial X}, \\
\frac{\partial N}{\partial T}=R * J * G(W) * F(N) N-M * N \\
+D\left(\frac{\partial^{2}}{\partial X^{2}}+\frac{\partial^{2}}{\partial Y^{2}}\right) N .
\end{gathered}
$$

Water is supplied uniformly at rate $A$ and is lost due to evaporation at rate $L W$. Plants take up water at rate $R * G(W) * F(N) * N$, where $G(W)$ is the functional response of plants to water and $F(N)$ is an increasing function that describes how plants increase water infiltration. Plant biomass dies at a rate $M * N$. For simplicity, Klausmeier used the linear functions $G(W)=W$ and $F(N)=N$, but the results are not too sensitive to the exact form of these functions. $J$ is the yield of plant biomass per unit water consumed. Plant biomass is lost only through densityindependent mortality and maintenance at rate $M N$. Water flows downhill (in the negative $X$ direction) at speed $V$, represented by the first-order derivative in (1). This is rapid compared with other processes in the model. Plant dispersal is modeled by a diffusion term in (2), with diffusion coefficient $D$ which represents diffusion both along the slope and transverse to it. Klausmeier analyzed this model both for a hillslope, for which $V \gg 0$, and flat land. His analysis showed that for given mortality rate $M$ and water flow speed $V$, there is a critical value of water input $A$ below which regular stripes form. As in the field, these model stripes tend to move uphill in time, as the vegetation grows on the upper side of the stripes which receive the water, but die off on the lower size, at which the water becomes exhausted. A three-variable (surface water, soil water, and plant biomass) extension of this model was developed by HilleRisLambers et al. [143], which showed that even when there was no slope, vegetation patterns can form. This model included the assumption that water could move in a fashion described by diffusion, which was necessary on flat surface to allow redistribution of water to areas occupied by vegetation. This achieves the same result of local self-reinforcement of existing vegetation coupled with suppression of vegetation nonlocally through depletion of water (see also [144]). Other models of this phenomenon include effects of seasonality [145] and changes in microtopography [146].

4.2. Peatland Bogs. As in the pattern described earlier, other regularly patterned landscapes found throughout the world are governed by some version of scale-dependent feedback, meaning that organisms grouped in patches modify their environment such that environmental factors have a positive effect on their growth at short distances (i.e., local facilitation) but a negative effect on their growth at long distances (i.e., large-scale inhibition, [11]). This was described earlier with respect to the striped patterns of hillside vegetation in semiarid lands [9] and the pattern of nutrient-rich tree islands in the oligotrophic marsh of the Everglades [106]. In wetlands, scale-dependent feedback often involves the accumulation of nutrients at the scale of the patch, which depletes nutrients at longer spatial scales [111]. This feedback produces wetlands that are patterned with a mazelike structure or with "strings" of hummocks and hollows aligned perpendicular to flow, depending on the slope of the landscape [147]. A major advance in ecosystem ecology has been the recognition of mechanisms that lead to self-organization of vegetative patterns on the wetland 
landscapes (e.g., $[111,112,148]$ ). These mechanisms involve biologically driven positive feedbacks.

Like the semiarid landscape, peatland bogs show vegetation patterns perpendicular to slopes. In these string patterns, relatively dry hummock ridges, which are highly vegetated, alternate with wet hollows that are sparsely vegetated $[3,149-151]$. These are oriented perpendicular to the slope. Rietkerk et al. [111] supplied a mathematical explanation for the emergence of this pattern based on positive feedback mechanisms. The peatland bog, of course, is different from the semiarid land ecosystem in the former's relative abundance of water. Nevertheless, water is a driving function in the pattern of the formation of bog pattern in creating differences in plant density. In this case, it is groundwater, rather than infrequent episodes of water which is running over the surface and infiltrating plant-occupied sites. The groundwater carries nutrients, which are limiting in these oligotrophic peatland ecosystems, and the plants need to gain their nutrients from the groundwater. A key mechanism is positive feedback between total plant productivity and thickness of the upper layer of peat (acrotelm) on slightly elevated dryer sites, mainly because of increased production of vascular plants [152-154]. As in the case of the semiarid vegetation, this pattern can start to develop on an initially homogeneous slope, but it is necessary to occur some initial slight irregularities, some wetter with less vegetation and some drier with more vegetation, randomly spaced on the slope, to get the process started. Positive feedback would tend to cause these initial deviations to grow in size. But an additional mechanism is needed to cause a regularly spaced pattern. This mechanism is the ponding of water that can occur behind any hummock for the case of water flowing downhill. This ponding forms a pressure head that is necessary for evapotranspiration to occur. Modeling suggests that regular string patterns develop only if the slope of a bog surface is steep enough that ponding of surface water upstream from hummocks can affect the distribution of future downhill hummocks. This is called the "water ponding" mechanism. Reitkerk et al. [111] used a deterministic, mechanistic model to show that the string patterns on sloping land and a mazelike pattern on flat land could be explained in terms of self-organization. The evapotranspiration creates a negative potential that allows nutrientladen groundwater to move toward the area of higher plant biomass, increasing their growth rates $[155,156]$. The authors call this second necessary mechanism the "nutrient accumulation" mechanism. Plant productivity is mainly limited by nutrient flows, so this mechanism may lead to the observed string patterns on slopes. On flat ground, the positive feedback nutrient accumulation mechanism still works because water can diffuse in the direction of vegetation where it is transpired. This creates hummocks and hollows but in a maze-like form without any regular pattern because the flow of water does not have the one distinct direction that an elevation gradient would create to form the regular pattern.

If, in the model of Rietkerk et al. [111], nutrient input, $N_{\text {in }}$, is high, then plant biomass is homogenously distributed in space because nutrients are available in excess.
Only when $N_{\text {in }}$ is decreased, making nutrients limiting, do patterns emerge because an instability (Turing instability) is then created. As in water-limited ecosystems, spatial selforganization of vegetation in nutrient-limited systems is a reaction to resource scarcity, where nutrients are redistributed to vegetation that is patterned to cover only part of the landscape. In the present model, vascular plants activate further growth by inducing nutrient mass flow toward the plants driven by transpiration, resulting in higher plant biomass, feeding back to even higher transpiration and more nutrient accumulation. Therefore, vascular plants function as activators, facilitating plant growth nearby (1-m scale). At the same time, nutrient levels decrease farther away $(10-\mathrm{m}$ scale), inhibiting plant growth. This resembles the "activatordepleted substrate" system described by (Gierer and Meinhardt 1972). In order to allow stable pattern formation, sufficient substrate (nutrients) must be supplied to maintain a steady activator (plants) production, while lateral flow of the substrate must be higher than the diffusion of the activator. The results of Rietkerk et al. [111] confirmed earlier model results, showing that redistribution of scarce resources may lead to fine-scale facilitative and coarse-scale competitive plant interactions in different ecosystems [144, 157-159].

4.3. Freshwater Marsh. The Florida Everglades, called the "river of grass", is a freshwater marsh characterized by rainfall seasonality and a broad shallow sheet flow southward along a slight elevational gradient (about $3 \mathrm{~cm}$ per $\mathrm{km}$ ). Like peatland, it displays a spatial pattern of undulating topography. However, unlike the peatland pattern described by Rietkerk et al. [111], in the Everglades, the undulations, called "ridge and slough" pattern, are parallel to the direction of flow [160]. This ridge and slough pattern has a mean horizontal periodicity of several tens of meters with vertical differences between ridges and sloughs of no more than a meter or so. The pattern is reminiscent of a braided river that occurs when rivers flow across a very flat, broad bed; that is, they often break into a series of channels that split and rejoin into a series of loops which isolate island after island [134].

Despite the apparent success of models in explaining the regular patterns of vegetation on slopes of peatlands and semiarid land, until recently, no models had appeared to successfully explain the existence of stable patterns of ridges and sloughs parallel to the flow of water in low gradient wetlands such as the Everglades. The ponding and nutrient accumulation mechanisms have not been able to explain the highly regular longitudinal (i.e., parallel-to-flow) vegetation patterning that occurs in the Everglades and elsewhere [148]. As Larsen and Harvey [161] point out, previous models of flow across a landscape tend to predict that parallel flows would eventually coalesce into a single channel (e.g., [162]) rather than the pattern of numerous parallel channels observed in areas of the Everglades.

One approach to an explanation of the patterning of ridges and sloughs parallel to the flow of water in the Everglades was provided by Larsen et al. [148] and Larsen and Harvey [161] who used a spatially explicit processbased numerical model to demonstrate how the slow-flowing 
water through the Everglades, under the right conditions, can create the patterns of ridge and sloughs characteristic of such wetlands. The movement of water in the Everglades differs from that of the previous two examples. In those cases, water flow is either underground, as in peat bogs, or occurs as infrequent pulses, as in the semi-arid lands. In the Everglades, there is almost continuous overland flow of water. Although the water flow is generally very slow, it may be sufficient for erosion and deposition processes to work, at least on more easily entrained flocculent material. One of the basic positive feedback processes in the model is the accretion of peat and accumulation of sediment in patches of emergent vegetation. Greater plant biomass has a positive effect on both processes, so is self-reinforcing. The other is the concentration of flow into narrower sloughs that occurs with the emergence of ridges, which increases the erosion through the entrainment of flocculent material in these low-elevation channels during the rainy season, when relatively strong pulses of water move downstream. This "floc" is preferentially deposited in the higher elevation ridge areas, where vegetation is denser and water flow is slower.

The hypothesis of Larsen et al. [148] and Larsen and Harvey [161] for the development of the ridge and slough landscape of the Everglades involves a number of details that will not be described here. The authors incorporated these into a landscape simulation model, which successfully predicted the emergence of the ridges and sloughs. But the model also showed that the emergence of this pattern was sensitive to the water-surface slope. On the one hand, if this high-flow slope is too high, a deep preferential channel can form, with continuous vegetation on either side. On the other hand, if the slope is too low, the redistribution of sediment needed for the ridge and slough pattern is not strong enough, and vegetation can expand to form homogeneous nondirectional patterns. Parts of the Everglades have experienced such a regime shift due to decreases in water flow. Therefore, the resilience of the ridge and slough landscape has only limited resilience to changes in the abiotic conditions, and the resilience appears to have been exceeded in parts of the Everglades where water flow patterns have been altered. The model of Larsen and Harvey [161] suggests that, due to a hysteresis effect, restoration of higher water flow may not be sufficient in itself to restore the original pattern of ridges and sloughs. The modeling here, while aimed specifically at the Everglades, may have much broader application to explaining wetland patterns worldwide.

Although the model developed by Larsen et al. [148] and Larsen and Harvey [161] appears to be plausible, it relies on the redistribution of flocculent material during periods of high flow. There is still question of whether the velocities achieved by flowing water, even under high rainfall conditions, can entrain flocculent material. Cohen et al. [163] suggest an alternative mechanism involving hydroperiod (length of time submerged) and depth, peat accretion, and peat redox potential. As peat accumulates at a given location, the water depth and hydroperiod at that location decrease, which increases aeration (i.e., increases soil redox potential), keeping in check further peat accretion.
However, sawgrass (Cladium jamaicense) tends to occupy higher elevations (ridges), and it deposits detritus that is higher in lignin than detritus from vegetation in the deeper water (sloughs). Thus, ridges tend to gain in soil accumulation faster than sloughs, but also to lose it faster through oxidation. Cohen et al. note that this creates a situation in which there are two alternative stable states, or states that have the same rate of peat accumulation; ridges and sloughs with a certain elevation difference. They further note that certain conditions can trigger a switch from an initially homogeneous depth to a pattern of alternative ridges and sloughs parallel to water flow. The mechanism for this switch is "discharge competence", or rate at which water can flow through the system. This is related to the idea that channels will develop to transport water in the most efficient way, minimizing energy loss [164-166]. If reorganization of the landscape into such a pattern from the initially homogeneous depth increases the discharge competence, there can be a spontaneous switch.

\section{Conclusion and Future Directions}

The study of self-organization in vegetation and in ecosystems in general is still relatively new. The first mathematical explanations for some of the more conspicuous vegetation patterns are less than two decades old, and explanations of others, such as the Everglades ridge and slough pattern, are much more recent. It is likely that many more patterns of vegetation that are explainable in terms of self-organization will be found, including subtle patterns whose existence will only be recognized through careful observation, including statistical analysis of spatial distributions. The attempt here has been to emphasize that both the sharp ecotones found between many vegetation types and the large-scale landscape patterns that have been recognized now over large areas of peatland, semiarid land, freshwater marsh, and other systems are created by similar combinations of positive and negative feedbacks, leading to the existence of bistability; that is, the existence of alternative stable states.

If much of the vegetation on the earth exists as one of two or more possible alternative stable states, then there is the possibility that changes in ecotones or patterns could be sudden, either because gradual change in environmental conditions eventually causes a switch that causes a rapid shift in vegetation, major disturbances, such as effects of storm surges on halophyte-glycophyte alternative states [48], or drought and fire on heath and forest alternative states [8]. The shift in the ecotone between ponderosa pine forest and pinon-juniper woodland in favor of the latter in New Mexico appears to have been a rapid shift, perhaps due to drought-induced mortality of ponderosa pines [167]. Other shifts, such as the upward shift in altitude of the northern hardwood-boreal forest ecotone in Vermont were also rapid but consistent with climatic change [168]. Changes in vegetation pattern are also being observed. The original ridge and slough landscape of parts of the Everglades is now degraded into irregular features $[160,161,169]$. Because such self-organizing patterns are characterized by hysteresis, 
restoration following a regime shift will be difficult or impossible. It is also possible that in many cases, selforganization, rather than creating patterns that are resilient to disturbances, may have the intrinsic property of taking a system to a point where it is vulnerable to disturbance. This possibility has been posed for salt marshes by van de Koppel et al. [170], indicating that there is much still to be learned. Even more fundamental theoretical developments are also possible in the understanding of spatial vegetation patterns. Many of these patterns are created by movement of water, and ecohydrology is a rapidly growing field. Borrowing from physics, ecohydrologists have proposed that there are underlying optimality principles in pattern formation, as noted earlier [164-166, 171]. Some of those proposed (e.g, $[172,173])$ have also been questioned [174], promising that the future of this field will be an exciting one.

Because large-scale changes in vegetation patterns will involve whole ecosystems, it is important to increase efforts to detect and understand the mechanisms of vegetation pattern, both ecotones and larger-scale landscape patterns (e.g., [175]). As experimental studies on the scale necessary for prediction of such large-scale changes will not be usually possible, simulation modeling using ecotone and vegetation pattern models (e.g., $[42,175,176]$ ) is needed to complement observational studies.

\section{References}

[1] V. Grimm, E. Revilla, U. Berger et al., "Pattern-oriented modeling of agent-based complex systems: lessons from ecology," Science, vol. 310, no. 5750, pp. 987-991, 2005.

[2] W. A. Macfadyen, "Vegetation patterns in the semi-desert plains of British Somaliland," Geography Journal, vol. 116, no. 4-6, pp. 199-211, 1950.

[3] D. R. Foster, G. A. King, P. H. Glaser, and H. E. Wright, "Origin of string patterns in boreal peatlands," Nature, vol. 306, no. 5940, pp. 256-258, 1983.

[4] D. L. DeAngelis, W. M. Post, and C. C. Travis, Positive Feedback in Natural Systems, Springer, Berlin, Germany, 1986.

[5] I. Noy-Meir, "Stability of grazing systems: an application of predator-prey graphs," Journal of Ecology, vol. 63, no. 2, pp. 459-481, 1975.

[6] R. M. May, "Thresholds and breakpoints in ecosystems with a multiplicity of stable states," Nature, vol. 269, no. 5628, pp. 471-477, 1977.

[7] M. Rietkerk and J. van de Koppel, "Alternate stable states and threshold effects in semi-arid grazing systems," Oikos, vol. 79, no. 1, pp. 69-76, 1997.

[8] P. S. Petraitis and R. E. Latham, "The importance of scale in testing the origins of alternative community states," Ecology, vol. 80, no. 2, pp. 429-442, 1999.

[9] C. A. Klausmeier, "Regular and irregular patterns in semiarid vegetation," Science, vol. 284, no. 5421, pp. 1826-1828, 1999.

[10] J. Bromley, J. Brouwer, A. P. Barker, S. R. Gaze, and C. Valentin, "The role of surface water redistribution in an area of patterned vegetation in a semi-arid environment, southwest Niger," Journal of Hydrology, vol. 198, no. 1-4, pp. 1-29, 1997.
[11] M. Rietkerk and J. van de Koppel, "Regular pattern formation in real ecosystems," Trends in Ecology and Evolution, vol. 23, no. 3, pp. 169-175, 2008.

[12] P. M. Groffman, J. S. Baron, T. Blett et al., "Ecological thresholds: the key to successful environmental management or an important concept with no practical application?" Ecosystems, vol. 9, no. 1, pp. 1-13, 2006.

[13] K. N. Suding and R. J. Hobbs, "Threshold models in restoration and conservation: a developing framework," Trends in Ecology and Evolution, vol. 24, no. 5, pp. 271-279, 2009.

[14] G.-R. Walther, E. Post, P. Convey et al., "Ecological responses to recent climate change," Nature, vol. 416, no. 6879, pp. 389395, 2002.

[15] J. R. Gosz, “Ecotone hierarchies," Ecological Applications, vol. 3, no. 3, pp. 369-376, 1993.

[16] P. G. Risser, "The status of the science examining ecotones. A dynamic aspect of landscape is the area of steep gradients between more homogeneous vegetation associations," BioScience, vol. 45, no. 5, pp. 318-325, 1995.

[17] L. R. Holdridge, "Determination of world plant formations from simple climatic data," Science, vol. 105, no. 2727, pp. 367-368, 1947.

[18] J. R. Gosz and P. J. H. Sharpe, "Broad-scale concepts for interactions of climate, topography, and biota at biome transitions," Landscape Ecology, vol. 3, no. 3-4, pp. 229-243, 1989.

[19] L. L. Arris and P. S. Eagleson, "Evidence of a physiological basis for the boreal-deciduous forest ecotone in North America," Vegetatio, vol. 82, no. 1, pp. 55-58, 1989.

[20] D. Goldblum and L. S. Rigg, "The deciduous forest-boreal forest ecotone," Geography Compass, vol. 4, no. 7, pp. 701$717,2010$.

[21] J. A. Wiens, C. S. Crawford, and J. R. Gosz, "Boundary dynamics: a conceptual framework for studying landscape ecosystems," Oikos, vol. 45, no. 3, pp. 421-427, 1985.

[22] M. Kamel, "Ecotone classification according to its origin," Pakistan Journal of Biological Sciences, vol. 6, pp. 1553-1563, 2003.

[23] Y. N. Araya, J. Silvertown, D. J. Gowing, K. J. McConway, H. Peter Linder, and G. Midgley, "A fundamental, ecohydrological basis for niche segregation in plant communities," New Phytologist, vol. 189, no. 1, pp. 253-258, 2011.

[24] B. E. Livingstone, The Distribution of the Upland Societies of Kent County, vol. 35, Botanical Gazette, Ann Arbor, Mich, USA, 1903.

[25] F. E. Clements, Research Methods in Ecology, University of Nebraska Publishing Company, Lincoln, Nebraska, 1905.

[26] M. M. Holland, P. G. Risser, and R. J. Naiman, Ecotones: The Role of Landscape Boundaries in the Management and Restoration of Changing Environments, Chapman and Hall, London, UK, 1991.

[27] M. Kent, W. J. Gill, R. E. Weaver, and R. P. Armitage, "Landscape and plant community boundaries in biogeography," Progress in Physical Geography, vol. 21, no. 3, pp. 315-353, 1997.

[28] K. D. Eggemeyer and S. Schwinning, "Biogeography of woody encroachment: why is mesquite excluded from shallow soils?" Ecohydrology, vol. 2, no. 1, pp. 81-87, 2009.

[29] T. T. Veblen and D. C. Lorenz, "Recent vegetation changes along the forest/steppe ecotone of northern Patagonia," Annals, vol. 78, no. 1, pp. 93-111, 1988.

[30] H. A. Gleason, "The structure and development of the plant association," Bulletin of the Torrey Botanical Club, vol. 44, pp. 463-481, 1917. 
[31] R. H. Whittaker, "Vegetation of the great smoky mountains," Ecological Monographs, vol. 26, pp. 1-80, 1975.

[32] T. Smith and M. Huston, "A theory of the spatial and temporal dynamics of plant communities," Vegetatio, vol. 83, no. 1-2, pp. 49-69, 1989.

[33] J. M. Emlen, Ecology: An Evolutionary Approach, AddisonWesley, Reading, Mass, USA, 1972.

[34] T. G. Siccama, "Vegetation, soil and climate on the Green Mountains of Vermont," Ecological Monographs, vol. 44, no. 3, pp. 325-349, 1974.

[35] H. J. Oosting, The Study of Plant Communities: An Introduction to Plant Ecology, W. H. Freeman and Company, San Francisco, Calif, USA, 2nd edition, 1955.

[36] R. M. Callaway, "Positive interactions among plants," Botanical Review, vol. 61, no. 4, pp. 306-349, 1995.

[37] F. E. Clements, Plant Succession: An Analysis of the Development of Vegetation, Carnegie Institution of Washington, Washington, DC, USA, 1916.

[38] A. G. Tansley, "The classification of vegetation and the concept of development," Journal of Ecology, vol. 8, pp. 118$149,1920$.

[39] J. B. Wilson and A. D. Q. Agnew, "Positive-feedback Switches in Plant Communities," Advances in Ecological Research, vol. 23, pp. 263-336, 1992.

[40] K. M. Lloyd, A. A. M. McQueen, B. J. Lee, R. C. B. Wilson, S. Walker, and J. B. Wilson, "Evidence on ecotone concepts from switch, environmental and anthropogenic ecotones," Journal of Vegetation Science, vol. 11, no. 6, pp. 903-910, 2000.

[41] A. D. Q. Agnew, J. B. Wilson, and M. T. Sykes, "A vegetation switch as the cause of a forest/mire ecotone in New Zealand," Journal of Vegetation Science, vol. 4, no. 2, pp. 273-278, 1993.

[42] J. G. Ehrenfeld, B. Ravit, and K. Elgersma, "Feedback in the plant-soil system," Annual Review of Environment and Resources, vol. 30, pp. 75-115, 2005.

[43] S. Hotes, A. P. Grootjans, H. Takahashi, K. Ekschmitt, and P. Poschlod, "Resilience and alternative equilibria in a mire plant community after experimental disturbance by volcanic ash," Oikos, vol. 119, no. 6, pp. 952-963, 2010.

[44] J. Jiang, D. L. DeAngelis, T. J. Smith III, S. Y. Teh, and H. L. Koh, "Spatial pattern formation of coastal vegetation in response to external gradients and positive feedbacks affecting soil porewater: a model study," Landscape Ecology, vol. 27, no. 1, pp. 109-119, 2012.

[45] C. A. Burchill and N. C. Kenkel, "Vegetation-environment relationships of an inland boreal salt pan," Canadian Journal of Botany, vol. 69, no. 4, pp. 722-732, 1991.

[46] R. E. Grosshans and N. C. Kenkel, "Dynamics of emergent vegetation along natural gradients of water depth and salinity in a prairie marsh: delayed influences of competition," UFS, (Delta Marsh) Annual Report 32, 1997.

[47] L. D. S. L. Sternberg, S. Y. Teh, S. M. L. Ewe, F. MirallesWilhelm, and D. L. DeAngelis, "Competition between hardwood hammocks and mangroves," Ecosystems, vol. 10, no. 4, pp. 648-660, 2007.

[48] S. Y. Teh, D. L. DeAngelis, L. D. S. L. Sternberg, F. R. MirallesWilhelm, T. J. Smith, and H. L. Koh, "A simulation model for projecting changes in salinity concentrations and species dominance in the coastal margin habitats of the Everglades," Ecological Modelling, vol. 213, no. 2, pp. 245-256, 2008.

[49] J. Jiang, D. Gao, and D. L. DeAngelis, "Towards a theory of ecotone resilience: coastal vegetation on a salinity gradient," Theoretical Population Biology, vol. 82, no. 1, pp. 29-37, 2012.
[50] J. Jiang, Mangroves on the move: predictions of storm surge effects on coastal vegetation [Ph.D. thesis], Department of Biology, University of Miami, 2012.

[51] W. E. Odum and C. C. McIvor, "Mangroves," in Ecosystems of Florida, R. L. Myers and J. J. Ewel, Eds., pp. 517-546, The University of Central Florida Press, Orlando, Fla, USA, 1990.

[52] F. H. Sklar and A. van der Valk, Tree islands of the Everglades, Kluwer Academic Publishers, Dordrecht, The Netherlands, 2002.

[53] L. D. S. L. Sternberg and P. K. Swart, "Utilization of freshwater and ocean water by coastal plants of southern Florida," Ecology, vol. 68, no. 6, pp. 1898-1905, 1987.

[54] M. S. Ross, J. J. O’Brien, and L. J. Flynn, "Ecological site classification of Florida Keys terrestrial habitats," Biotropica, vol. 24, no. 4, pp. 488-502, 1992.

[55] J. R. Snyder, A. Herndon, and W. B. J. Robertson, "South Florida rockland," in Ecosystems of Florida, R. L. Myers and J. J. Ewel, Eds., pp. 346-359, The University of Central Florida Press, Orlando, Fla, USA, 1990.

[56] J. A. Jiménez and K. Sauter, "Structure and dynamics of mangrove forests along a flooding gradient," Estuaries, vol. 14, no. 1, pp. 49-56, 1991.

[57] N. C. Kenkel, A. L. McIlraith, C. A. Burchill, and G. Jones, "Competition and the response of three plant species to a salinity gradient," Canadian Journal of Botany, vol. 69, no. 11, pp. 2497-2502, 1991.

[58] M. K. G. La Peyre, J. B. Grace, E. Hahn, and I. A. Mendelssohn, "The importance of competition in regulating plant species abundance along a salinity gradient," Ecology, vol. 82, no. 1, pp. 62-69, 2001.

[59] J. A. Silander and J. Antonovics, "Analysis of interspecific interactions in a coastal plant community-a perturbation approach," Nature, vol. 298, no. 5874, pp. 557-560, 1982.

[60] G. Lin and L. D. S. L. Sternberg, "Effect of growth form, salinity, nutrient and sulfide on photosynthesis, carbon isotope discrimination and growth of red mangrove (Rhizophora mangle L.)," Australian Journal of Plant Physiology, vol. 19, no. 5, pp. 509-517, 1992.

[61] J. B. Passioura, M. C. Ball, and J. H. Knight, "Mangroves may salinize the soil and in so doing limit their transpiration rate," Functional Ecology, vol. 6, no. 4, pp. 476-481, 1992.

[62] K. M. Volkmar, Y. Hu, and H. Steppuhn, "Physiological responses of plants to salinity: a review," Canadian Journal of Plant Science, vol. 78, no. 1, pp. 19-27, 1998.

[63] F. Accatino, C. De Michele, R. Vezzoli, D. Donzelli, and R. J. Scholes, "Tree-grass co-existence in savanna: interactions of rain and fire," Journal of Theoretical Biology, vol. 267, no. 2, pp. 235-242, 2010.

[64] R. W. Mutch, "Woodland fires and ecosystems - an hypothesis," Ecology, vol. 51, pp. 1046-1051, 1970.

[65] E. N. Transeau, “The prairie peninsula," Ecology, vol. 16, pp. 423-437, 1935.

[66] C. Loehle, B.-L. Li, and R. C. Sundell, "Forest spread and phase transitions at forest-prairie ecotones in Kansas, U.S.A," Landscape Ecology, vol. 11, no. 4, pp. 225-235, 1996.

[67] W. G. Abrahamson, "Species response to fire on the Florida Lake Wales Ridge," American Journal of Botany, vol. 71, no. 1, pp. 35-43, 1984.

[68] E. A. Boughton, P. F. Quintana-Ascencio, E. S. Menges, and R. K. Boughton, "Association of ecotones with relative elevation and fire in an upland Florida landscape," Journal of Vegetation Science, vol. 17, no. 3, pp. 361-368, 2006. 
[69] M. Vilà, F. Lloret, E. Ogheri, and J. Terradas, "Positive firegrass feedback in Mediterranean Basin woodlands," Forest Ecology and Management, vol. 147, no. 1, pp. 3-14, 2001.

[70] D. C. Odion, M. A. Moritz, and D. A. Dellasala, "Alternative community states maintained by fire in the Klamath Mountains, USA," Journal of Ecology, vol. 98, no. 1, pp. 96-105, 2010.

[71] R. E. Ricklefs, The Economy of Nature, Chiron Press, Portland, Ore, USA, 1976.

[72] J. M. Briggs, A. K. Knapp, J. M. Blair et al., "An ecosystem in transition: causes and consequences of the conversion of mesic grassland to shrubland," BioScience, vol. 55, no. 3, pp. 243-254, 2005.

[73] B. H. Walker and I. Noy-Meir, "Aspects of stability and resilience of savanna ecosystems," in Ecology of Tropical Savannas, B. J. Huntley and B. H. Walker, Eds., pp. 577-590, Springer, Berlin, Germany, 1982.

[74] R. J. Scholes and S. R. Archer, "Tree-grass interactions in Savannas," Annual Review of Ecology and Systematics, vol. 28, pp. 517-544, 1997.

[75] J. M. Briggs, A. K. Knapp, and B. L. Brock, "Expansion of woody plants in tallgrass prairie: a fifteen-year study of fire and fire-grazing interactions," American Midland Naturalist, vol. 147, no. 2, pp. 287-294, 2002.

[76] A. C. Staver, S. Archibald, and S. A. Levin, "The global extent and determinants of savanna and forest as alternative biome states," Science, vol. 334, pp. 230-232, 2011.

[77] H. H. Shugart, W. R. Emanuel, D. C. West, and D. L. DeAngelis, "Environmental gradients in a simulation model of a beech-yellow-poplar stand," Mathematical Biosciences, vol. 50, no. 3-4, pp. 163-170, 1980.

[78] N. Yamamura, "A mathematical approach to spatial distribution and temporal succession in plant communities," Bulletin of Mathematical Biology, vol. 38, no. 5, pp. 517-526, 1976.

[79] M. Y. Bader, M. Rietkerk, and A. K. Bregt, "A simple spatial model exploring positive feedbacks at tropical alpine treelines," Arctic, Antarctic, and Alpine Research, vol. 40, no. 2, pp. 269-278, 2008.

[80] G. P. Malanson, N. Xiao, and K. J. Alftine, "A simulation test of the resource-averaging of ecotone formation," Journal of Vegetation Science, vol. 12, no. 6, pp. 743-748, 2001.

[81] T. Wiegand, J. J. Camarero, N. Rüger, and E. Gutiérrez, "Abrupt population changes in treeline ecotones along smooth gradients," Journal of Ecology, vol. 94, no. 4, pp. 880$892,2006$.

[82] R. O. Slatyer and I. R. Noble, "Dynamic of montane tree lines," in Landscape Boundaries: Consequences of Biotic Diversity and Ecological Flows, A. J. Hansen and F. di Castri, Eds., pp. 346-359, Springer, New York, NY, USA, 1992.

[83] F. K. Holtmeier, Mountain Timberlines: Ecology, Patchiness, and Dynamics, Kluwer, Dordrecht, The Netherlands, 2003.

[84] K. J. Alftine and G. P. Malanson, "Directional positive feedback and pattern at an alpine tree line," Journal of Vegetation Science, vol. 15, no. 1, pp. 3-12, 2004.

[85] A. G. Bunn, L. J. Graumlich, and D. L. Urban, "Trends in twentieth-century tree growth at high elevations in the Sierra Nevada and White Mountains, USA," Holocene, vol. 15, no. 4, pp. 481-488, 2005.

[86] R. V. Solé and S. C. Manrubia, "Are rainforests self-organized in a critical state?" Journal of Theoretical Biology, vol. 173, no. 1, pp. 31-40, 1995.

[87] M. F. Bekker, "Positive feedback between tree establishment and patterns of subalpine forest advancement, Glacier
National Park, Montana, U.S.A," Arctic, Antarctic, and Alpine Research, vol. 37, no. 1, pp. 97-107, 2005.

[88] T. B. Nishimura and T. Kohyama, "Formation and maintenance of community boundaries in a sub-alpine forest landscape in northern Japan," Journal of Vegetation Science, vol. 13, no. 4, pp. 555-564, 2002.

[89] P. H. Martin, T. J. Fahey, and R. E. Sherman, "Vegetation zonation in a Neotropical montane forest: environment, disturbance, and ecotones," Biotropica, vol. 43, no. 5, pp. 533$543,2010$.

[90] H. C. Cowles, Ecological Relations of the Vegetation on the Sand Dunes of Lake Michigan, University of Chicago Press, Chicago, Ill, USA, 1899.

[91] J. S. Olson, "Rates of succession and soil changes on southern Lake Michigan sand dunes," Botanical Gazette, vol. 119, no. 3, pp. 125-170, 1958.

[92] E. B. Adema and A. P. Grootjans, "Possible positive-feedback mechanisms: plants change abiotic soil parameters in wet calcareous dune slacks," Plant Ecology, vol. 167, no. 1, pp. 141-149, 2003.

[93] F. A. Einhellig et al., "Allelopathy: current status and future goals," in Allelopathy, K. Dakshini, Ed., ACS Symposium Series, American Chemical Society, Washington, DC, USA, 1995.

[94] C. H. Muller, "The role of chemical inhibition (allelopathy) in vegetational composition," Bulletin of the Torrey Botanical Club, vol. 93, no. 5, pp. 332-351, 1966.

[95] J. K. McPherson, C. H. Chou, and C. H. Muller, "Allelopathic constituents of the chaparral shrub Adenostoma fasciculatum," Phytochemistry, vol. 10, no. 12, pp. 2925-2933, 1971.

[96] N. H. Fischer, G. B. Williamson, J. D. Weidenhamer, and D. R. Richardson, "In search of allelopathy in the Florida scrub: the role of terpenoids," Journal of Chemical Ecology, vol. 20, no. 6, pp. 1355-1380, 1994.

[97] C. B. Gentle and J. A. Duggin, "Allelopathy as a competitive strategy in persistent thickets of Lantana camara L. in three Australian forest communities," Plant Ecology, vol. 132, no. 1, pp. 85-95, 1997.

[98] A. G. van der Valk and B. G. Warner, "The development of patterned mosaic landscapes: an overview," Plant Ecology, vol. 200, no. 1, pp. 1-7, 2009.

[99] G. T. Prance and G. B. Schaller, "Preliminary study of some vegetation types of the pantanal, mato grosso, Brazil," Brittonia, vol. 34, no. 2, pp. 228-251, 1982.

[100] T. S. McCarthy and W. N. Ellery, "The effect of vegetation on soil and ground water chemistry and hydrology of islands in the seasonal swamps of the Okavango Fan, Botswana," Journal of Hydrology, vol. 154, no. 1-4, pp. 169-193, 1994.

[101] P. Macek, E. Rejmánková, and R. Fuchs, "Biological activities as patchiness driving forces in wetlands of northern Belize," Oikos, vol. 118, no. 11, pp. 1687-1694, 2009.

[102] P. H. Glaser, The Ecology of Patterned Boreal Peatlands of Northern Minnesota: a Community Profile, vol. 85 of U.S. Fish and Wildife, Service Representative, Report, Washington, DC, USA, 1987.

[103] P. H. Glaser, "Raised bogs in eastern North Americaregional controls for species richness and floristic assemblages," Journal of Ecology, vol. 80, no. 3, pp. 535-554, 1992.

[104] C. J. Richardson, "Freshwater wetlands", in North American Terrestrial Vegetation, M. G. Barbour and W. D. Billings, Eds., pp. 450-499, Cambridge University Press, New York, NY, USA, 2000.

[105] P. R. Wetzel, A. G. Van Der Valk, S. Newman et al., "Heterogeneity of phosphorus distribution in a patterned 
landscape, the Florida Everglades," Plant Ecology, vol. 200, no. 1, pp. 83-90, 2009.

[106] P. D'Odorico, V. Engel, J. A. Carr, S. F. Oberbauer, M. S. Ross, and J. P. Sah, "Tree-Grass Coexistence in the Everglades Freshwater System," Ecosystems, vol. 14, no. 2, pp. 298-310, 2011.

[107] M. S. Ross, S. Mitchell-Bruker, J. P. Sah et al., "Interaction of hydrology and nutrient limitation in the Ridge and Slough landscape of the southern Everglades," Hydrobiologia, vol. 569, no. 1, pp. 37-59, 2006.

[108] X. Wang, L. O. Sternberg, M. S. Ross, and V. C. Engel, "Linking water use and nutrient accumulation in tree island upland hammock plant communities in the Everglades National Park, USA," Biogeochemistry, vol. 104, no. 1-3, pp. 133-146, 2011.

[109] J. Douglas Oliver and T. Legović, "Okefenokee marshland before, during and after nutrient enrichment by a bird rookery," Ecological Modelling, vol. 43, no. 3-4, pp. 195-223, 1988.

[110] M. D. Lowman and H. B. Rinker, Forest Canopies, Elsevier Science and Technology, 2004.

[111] M. Rietkerk, S. C. Dekker, M. J. Wassen, A. W. M. Verkroost, and M. F. P. Bierkens, "A putative mechanism for bog patterning," American Naturalist, vol. 163, no. 5, pp. 699-708, 2004.

[112] T. J. Givnish, J. C. Volin, V. D. Owen, V. C. Volin, J. D. Muss, and P. H. Glaser, "Vegetation differentiation in the patterned landscape of the central Everglades: importance of local and landscape drivers," Global Ecology and Biogeography, vol. 17, no. 3, pp. 384-402, 2008.

[113] S. Walker, J. B. Wilson, J. B. Steel et al., "Properties of ecotones: evidence from five ecotones objectively determined from a coastal vegetation gradient," Journal of Vegetation Science, vol. 14, no. 4, pp. 579-590, 2003.

[114] B. K. van Wesenbeeck, J. van de Koppel, P. M. J. Herman et al., "Potential for sudden shifts in transient systems: distinguishing between local and landscape-scale processes," Ecosystems, vol. 11, no. 7, pp. 1133-1141, 2008.

[115] J. van de Koppel, P. M. J. Herman, P. Thoolen, and C. H. R. Heip, "Do alternate stable states occur in natural ecosystems? Evidence from a tidal flat," Ecology, vol. 82, no. 12, pp. 34493461, 2001.

[116] J. Carr, P. D'Odorico, K. McGlathery, and P. Wiberg, "Stability and bistability of seagrass ecosystems in shallow coastal lagoons: role of feedbacks with sediment resuspension and light attenuation," Journal of Geophysical Research G, vol. 115, no. 3, Article ID G03011, 2010.

[117] M. Scheffer, S. Carpenter, J. A. Foley, C. Folke, and B. Walker, "Catastrophic shifts in ecosystems," Nature, vol. 413, no. 6856, pp. 591-596, 2001.

[118] M. Scheffer, Critical Transitions in Nature and Society, Princeton University Press, Princeton, NJ, USA, 2009.

[119] B. E. Beisner, D. T. Haydon, and K. Cuddington, "Alternative stable states in ecology," Frontiers in Ecology and the Environment, vol. 1, pp. 376-382, 2003.

[120] R. P. Neilson, "Transient ecotone response to climatic change: some conceptual and modelling approaches," Ecological Applications, vol. 3, no. 3, pp. 385-395, 1993.

[121] C. S. Holling, "Resilience and stability of ecological systems," Annual Review of Ecology and Systematics, vol. 4, pp. 1-23, 1973.

[122] L. H. Gunderson, "Ecological resilience-in theory and application," Annual Review of Ecology and Systematics, vol. 31, pp. 425-439, 2000.
[123] M. Scheffer, S. H. Hosper, M. L. Meijer, B. Moss, and E. Jeppesen, "Alternative equilibria in shallow lakes," Trends in Ecology and Evolution, vol. 8, no. 8, pp. 275-279, 1993.

[124] M. Scheffer, Ecology of Shallow Lakes, Chapman and Hall, London, UK, 1998.

[125] D. D. Briske, S. D. Fuhlendorf, and F. E. Smeins, "A unified framework for assessment and application of ecological thresholds," Rangeland Ecology and Management, vol. 59, no. 3, pp. 225-236, 2006.

[126] S. R. Carpenter, D. Ludwig, and W. A. Brock, "Management of eutrophication for lakes subject to potentially irreversible change," Ecological Applications, vol. 9, no. 3, pp. 751-771, 1999.

[127] C. Folke, S. Carpenter, B. Walker et al., "Regime shifts, resilience, and biodiversity in ecosystem management," Annual Review of Ecology, Evolution, and Systematics, vol. 35, pp. 557-581, 2004.

[128] J. K. Petersen, J. W. Hansen, M. B. Laursen, P. Clausen, J. Carstensen, and D. J. Conley, "Regime shift in a coastal marine ecosystem," Ecological Applications, vol. 18, no. 2, pp. 497-510, 2008.

[129] T. K. Stringham, W. C. Krueger, and P. L. Shaver, "State and transition modeling: an ecological process approach," Journal of Range Management, vol. 56, no. 2, pp. 106-113, 2003.

[130] G. P. Malanson, "Effects of feedbacks and seed rain on ecotone patterns," Landscape Ecology, vol. 12, no. 1, pp. 2738, 1997.

[131] J. M. Peterson and S. S. Bell, "Tidal events and salt-marsh structure influence black mangrove (Avicennia germinans) recruitment across an ecotone," Ecology, vol. 93, pp. 1648$1658,2012$.

[132] A. H. Baldwin and I. A. Mendelssohn, "Effects of salinity and water level on coastal marshes: an experimental test of disturbance as a catalyst for vegetation change," Aquatic Botany, vol. 61, no. 4, pp. 255-268, 1998.

[133] G. D. Steyer, K. F. Cretini, S. Piazza, L. A. Sharp, G. A. Snedden, and S. Sapkota, "Hurricane influences on vegetation community change in coastal Louisiana," OpenFile Report 2010-1105, U.S. Department of the Interior, U.S. Geological Survey, 2010.

[134] P. Ball, The Self-Made Tapestry: Pattern Formation in Nature, Oxford University Press, New York, NY, USA, 1999.

[135] S. Camazine, J.-L. Deneubourg, N. R. Franks, J. Sneyd, G. Theraulaz, and E. Bonabeau, Self-organization in Biological Systems, Princeton Studies in Complexity, Princeton University Press, Princeton, NJ, USA, 2001.

[136] A. Turing, "The chemical basis for morphogenesis," Philosophical Transactions of the Royal Society of London, vol. 237, pp. 37-72, 1952.

[137] A. Gierer and H. Meinhardt, "A theory of biological pattern formation," Kybernetik, vol. 12, no. 1, pp. 30-39, 1972.

[138] H. Meinhardt and A. Gierer, "Pattern formation by local selfactivation and lateral inhibition," BioEssays, vol. 22, no. 8, pp. 753-760, 2000.

[139] A. J. Koch and H. Meinhardt, "Biological pattern formation: from basic mechanisms to complex structures," Reviews of Modern Physics, vol. 66, no. 4, pp. 1481-1507, 1994.

[140] A. Okubo, Diffusion and Ecological Problems: Mathematical Models, vol. 10 of Biomathematics, Springer, Berlin, Germany, 1980.

[141] S. A. Levin, "The problem of pattern and scale in ecology," Ecology, vol. 73, no. 6, pp. 1943-1967, 1992.

[142] C. Montaña, J. Lopez-Portillo, and A. Mauchamp, "The response of two woody species to the conditions created by 
a shifting ecotone in an arid ecosystem," Journal of Ecology, vol. 78, no. 3, pp. 789-798, 1990.

[143] R. HilleRisLambers, M. Rietkerk, F. van den Bosch, H. H. T. Prins, and H. De Kroon, "Vegetation pattern formation in semi-arid grazing systems," Ecology, vol. 82, no. 1, pp. 50-61, 2001.

[144] R. Lefever and O. Lejeune, "On the origin of tiger bush," Bulletin of Mathematical Biology, vol. 59, no. 2, pp. 263-294, 1997.

[145] V. Guttal and C. Jayaprakash, "Self-organization and productivity in semi-arid ecosystems: implications of seasonality in rainfall," Journal of Theoretical Biology, vol. 248, no. 3, pp. 490-500, 2007.

[146] P. M. Saco, G. R. Willgoose, and G. R. Hancock, "Ecogeomorphology of banded vegetation patterns in arid and semi-arid regions," Hydrology and Earth System Sciences, vol. 11, no. 6, pp. 1717-1730, 2007.

[147] M. B. Eppinga, M. Rietkerk, W. Borren, E. D. Lapshina, W. Bleuten, and M. J. Wassen, "Regular surface patterning of peatlands: confronting theory with field data," Ecosystems, vol. 11, no. 4, pp. 520-536, 2008.

[148] L. G. Larsen, J. W. Harvey, and J. P. Crimaldi, "A delicate balance: ecohydrological feedbacks governing landscape morphology in a lotic peatland," Ecological Monographs, vol. 77, no. 4, pp. 591-614, 2007.

[149] Y. Sakaguchi, On the Genesis of Banks and Hollows in Peat Bogs: An Explanation by a Thatch Line Theory, vol. 12, Bulletin of the Department of Geography University of Tokyo, 1980.

[150] R. A. Lindsay, J. Riggall, and F. Burd, "The use of small-scale surface patterns in the classification of British peatlands," Aquilo Series Botanica, vol. 21, pp. 69-79, 1985.

[151] L. R. Belyea and J. Lancaster, "Inferring landscape dynamics of bog pools from scaling relationships and spatial patterns," Journal of Ecology, vol. 90, no. 2, pp. 223-234, 2002.

[152] G. A. Alexandrov, "A spatially distributed model of raised bog relief," in Wetland Modelling, W. J. Mitsch, M. Straskraba, and S. E. Jorgensen, Eds., p. 41, Elsevier, Amsterdam, The Netherlands, 1988.

[153] D. K. Swanson and D. F. Grigal, "A simulation model of mire patterning," Oikos, vol. 53, no. 3, pp. 309-314, 1988.

[154] L. R. Belyea and R. S. Clymo, "Feedback control of the rate of peat formation," Proceedings of the Royal Society B, vol. 268, no. 1473 , pp. 1315-1321, 2001.

[155] A. H. Fitter and R. K. M. Hay, Environmental Physiology of Plants, Academic Press, London, UK, 1983.

[156] H. Marschner, Mineral Nutrition of Higher, Plants. Academic Press, London, UK, 1995.

[157] P. Couteron and O. Lejeune, "Periodic spotted patterns in semi-arid vegetation explained by a propagation-inhibition model," Journal of Ecology, vol. 89, no. 4, pp. 616-628, 2001.

[158] O. Lejeune, M. Tlidi, and P. Couteron, "Localized vegetation patches: a self-organized response to resource scarcity," Physical Review E, vol. 66, no. 1, Article ID 010901, 2002.

[159] M. Rietkerk, M. C. Boerlijst, F. van Langevelde et al., "Selforganization of vegetation in arid ecosystems," American Naturalist, vol. 160, no. 4, pp. 524-530, 2002.

[160] C. McVoy, W. Park Said, J. Obeysekera, J. VanArman, and T. Dreschel, Landscapes and Hydrology of the Pre-Drainage Everglades, University Press of Florida, Gainesville, Fla, USA, 2011.

[161] L. G. Larsen and J. W. Harvey, "How vegetation and sediment transport feedbacks drive landscape change in the Everglades and wetlands worldwide," American Naturalist, vol. 176, no. 3, pp. E66-E79, 2010.

[162] A. Rinaldo, I. Rodriguez-Iturbe, and R. Rigon, "Channel networks," Annual Review of Earth and Planetary Sciences, vol. 26, pp. 289-327, 1998.

[163] M. J. Cohen, D. L. Watts, J. B. Heffernan, and T. Z. Osborne, "Reciprocal biotic control on hydrology, nutrient gradients, and landform in the greater everglades," Critical Reviews in Environmental Science and Technology, vol. 41, no. 1, pp. 395429, 2011.

[164] I. Rodriguez-Iturbe, E. J. Ijjasz-Vasquez, R. L. Bras, and D. G. Tarboton, "Power law distributions of discharge mass and energy in river basins," Water Resources Research, vol. 28, no. 4, p. 1089, 1992.

[165] R. Rigon, A. Rinaldo, I. Rodriguez-Iturbe, R. L. Bras, and E. Ijjasz- Vasquez, "Optimal channel networks: a framework for the study of river basin morphology," Water Resources Research, vol. 29, no. 6, pp. 1635-1646, 1993.

[166] C. Gaucherel, "Self-organization of patchy landscapes: hidden optimization ofecological processes," Journal of Ecosystem and Ecography. In press.

[167] C. D. Allen and D. D. Breshears, "Drought-induced shift of a forest-woodland ecotone: rapid landscape response to climate variation," Proceedings of the National Academy of Sciences of the United States of America, vol. 95, no. 25, pp. 14839-14842, 1998.

[168] B. Beckage, B. Osborne, D. G. Gavin, C. Pucko, T. Siccama, and T. Perkins, "A rapid upward shift of a forest ecotone during 40 years of warming in the Green Mountains of Vermont," Proceedings of the National Academy of Sciences of the United States of America, vol. 105, no. 11, pp. 4197-4202, 2008.

[169] L. Larsen, N. Aumen, C. Bernhardt et al., "Recent and historic drivers of landscape change in the everglades ridge, Slough, and Tree Island Mosaic," Critical Reviews in Environmental Science and Technology, vol. 41, no. 1, pp. 344-381, 2011.

[170] J. van de Koppel, D. van der Wal, J. P. Bakker, and P. M. Herman, "Self-organization and vegetation collapse in salt marsh ecosystems," The American Naturalist, vol. 165, no. 1, pp. E1-E12, 2005.

[171] G. D. Jenerette, G. A. Barron-Gafford, A. J. Guswa, J. J. Mcdonnell, and J. C. Villegas, "Organization of complexity in water limited ecohydrology," Ecohydrology, vol. 5, no. 2, pp. 184-199, 2011.

[172] P. S. Eagleson, "Ecological optimality in water-limited natural soil-vegetation systems, 1 . Theory and hypothesis," Water Resources Research, vol. 18, no. 2, pp. 325-340, 1982.

[173] P. S. Eagleson and T. E. Tellers, "Ecological optimality in water-limited natural soil-vegetation systems, 2. Tests and applications," Water Resources Research, vol. 18, no. 2, p. 341, 1982.

[174] A. J. Kerkhoff, S. N. Martens, and B. T. Milne, "An ecological evaluation of Eagleson's optimality hypotheses," Functional Ecology, vol. 18, no. 3, pp. 404-413, 2004.

[175] M. Gottfried, H. Pauli, and G. Grabherr, "Prediction of vegetation patterns at the limits of plant life: a new view of the alpine-nival ecotone," Arctic and Alpine Research, vol. 30, no. 3, pp. 207-221, 1998.

[176] S. Kéfi, M. Rietkerk, M. van Baalen, and M. Loreau, "Local facilitation, bistability and transitions in arid ecosystems," Theoretical Population Biology, vol. 71, no. 3, pp. 367-379, 2007. 

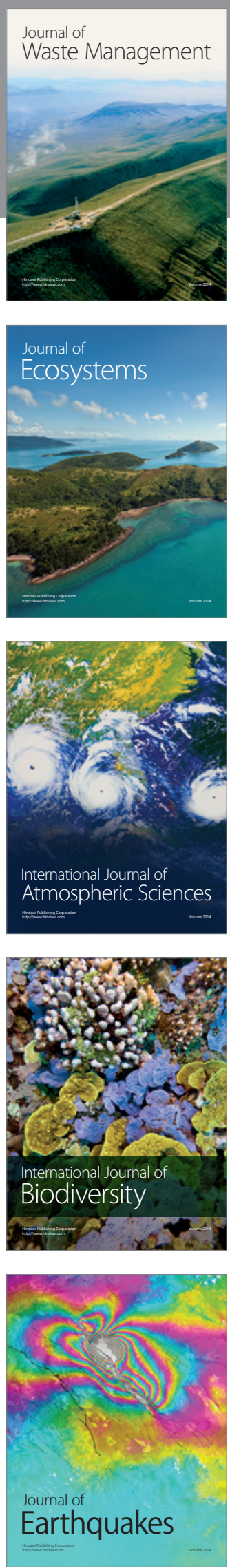
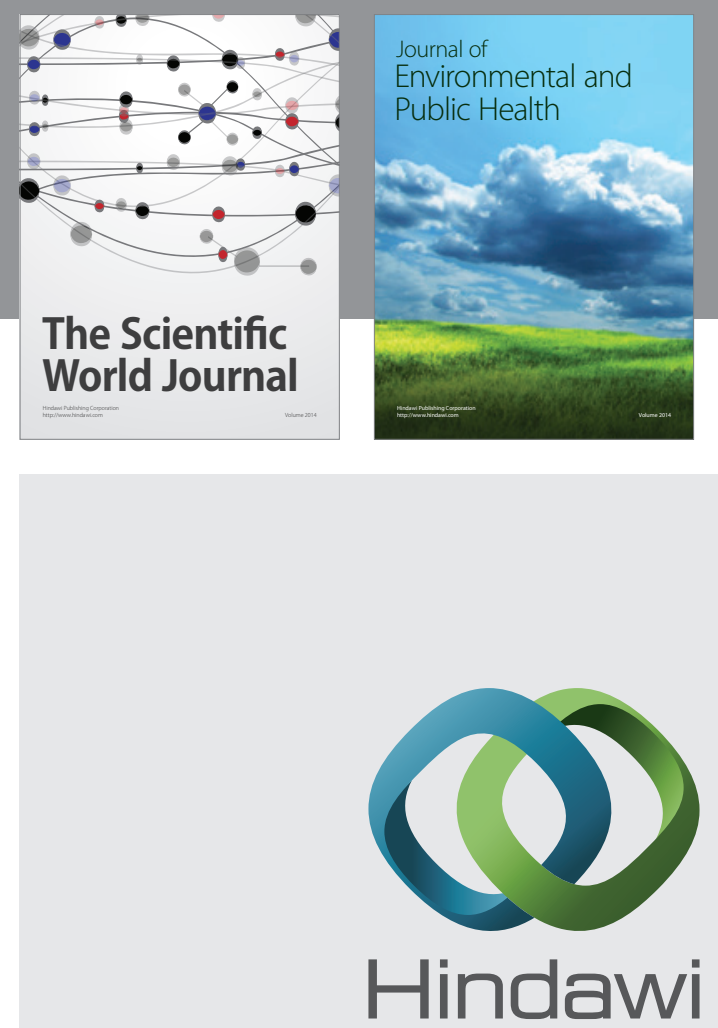

Submit your manuscripts at

http://www.hindawi.com
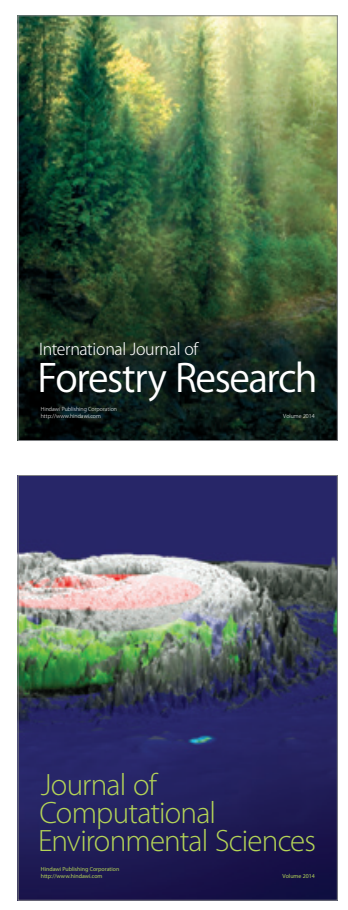
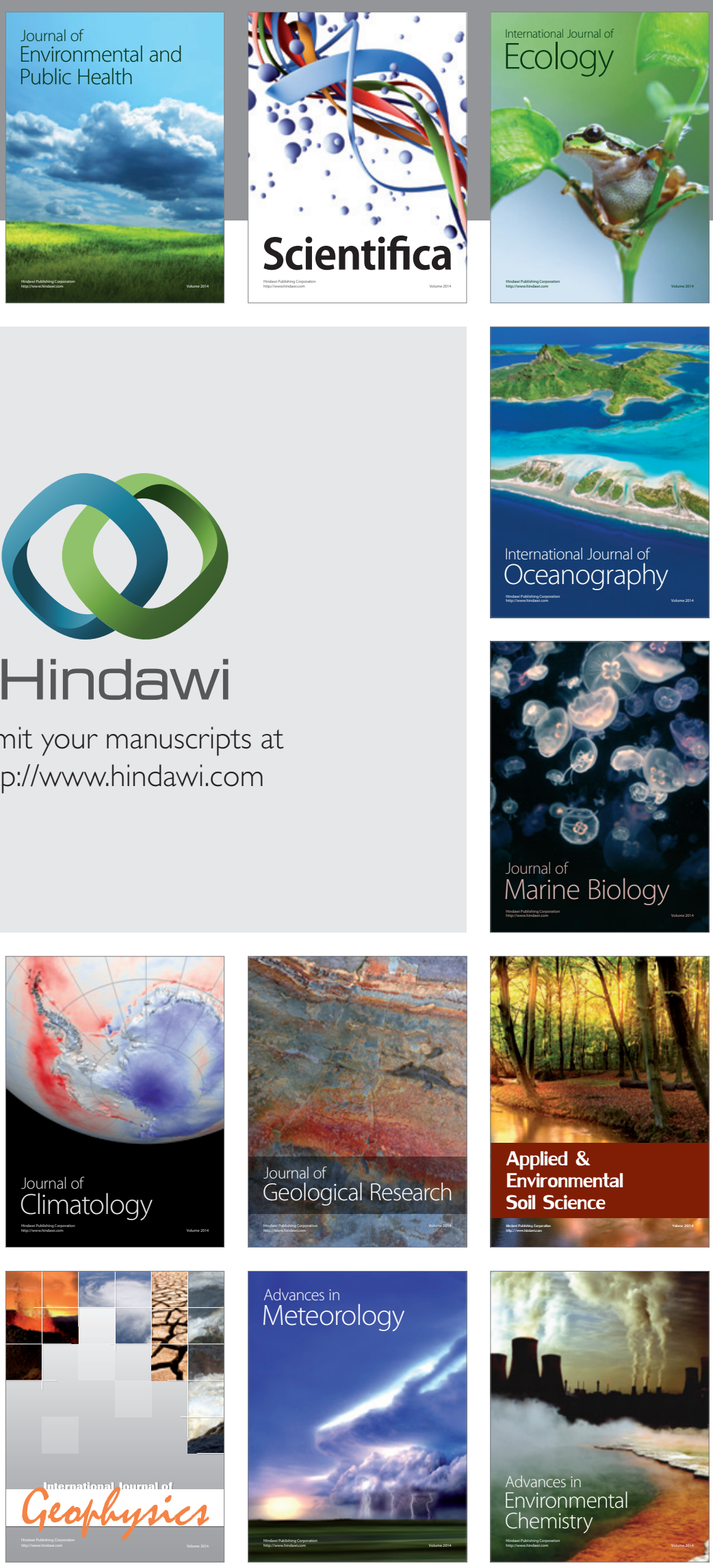